\title{
Ñande reko: fundamentos dos conhecimentos tradicionais ambientais Guaraní
}

\author{
Ñande reko: Guaraní traditional environmental \\ knowledge fundamentals
}

\author{
Francisco Silva Noelli ${ }^{1}$ \\ Giovana Cadorin Votre ${ }^{2}$ \\ Marcos César Pereira Santos ${ }^{3}$ \\ Diego Dias Pavei ${ }^{4}$ \\ Juliano Bitencourt Campos ${ }^{5}$
}

DOI: https://doi.org/10.26512/rbla.v11i1.23636

Recebido em janeiro/2019 e aceito em março/2019.

\section{Resumo}

Este artigo apresenta alguns aspectos fundamentais do manejo de recursos ambientais e da territorialidade Guaraní no Brasil meridional e Bacia Platina. A partir de uma vasta base de dados interdisciplinares legada por vários autores desde o século XVI, temos por hipótese que os Guaraní reproduziam em seus assentamentos um sistema de conhecimentos originalmente desenvolvidos na Amazônia, que configurava a forma e a função da sua cultura material e dos seus conhecimentos ecológicos e botânicos. A base da subsistência era a policultura agroflorestal de plantas alimentícias, medicinais e matérias-primas transportadas e manejadas na longa duração, incluindo-se as espécies adotadas nas novas áreas que dominavam. Tais características tornavam os Guaraní aptos a fundar assentamentos, manejar plantas e animais em diversos ecossistemas e a modificar as paisagens vegetais para prover sua segurança alimentar.

Palavras-chave: Arqueologia. História. Etnobotânica. Segurança alimentar. Manejo de recursos.

\footnotetext{
Abstract

This article presents some major issues of Guaranís environmental resource management in southern Brazil and in the Río de La Plata Basin. From a wide interdisciplinary database bequeathed by different authors since 16th century, it is possible to adopt as hypothesis that the Guaraní reproduced at their settlements a system of knowledge originally designed in the Amazon, framing the form, and function of their material culture, ecological, and botanical

${ }^{1}$ Professor aposentado da UEM/PR, pesquisador associado do LAEE/UEM e do LAPIS/ UNESC/SC. chico.noelli@gmail.com.br.

${ }^{2}$ Graduanda em Ciências Biológicas, Bolsista PIBIC/CNPq (Edital nº120/2018/PROACA), LAPIS/UNESC/Criciúma/SC. giovana.cadorin@hotmail.com.

${ }^{3}$ Pesquisador associado do NEPA/UNIOESTE/PR e do LAPIS/UNESC/Criciúma/SC. marcoscesar@unesc.net.

${ }^{4}$ Mestrando do PPGAnt/UFPel/Pelotas/RS, pesquisador do LAPIS/UNESC/Criciúma/SC. diego.pavei@unesc.net.

${ }^{5}$ Professor do PPGCA, Coordenador do LAPIS/UNESC/Criciúma/SC. jbi@unesc.net.
} 
knowledge and practices. The basis of subsistence was the agroforestry polyculture of a plant of food, medicinal, and raw material transported and managed in the long term, including more species adopted in the new conquered areas. These characteristics made the Guaraní able to found settlements, manage plants and animal in diverse ecosystems, and to modify vegetation landscapes to provide food security.

Keywords: Archaeology. History. Ethnobotany. Food security. Resource management.

la agricultura Guaraní responde a una lógica cíclica que no tiene nada que ver con la optimización ascendente de rendimientos o con una noción de perpetuo progreso económico... Héctor Keller (2012:28)

A linguagem, a cultura e o ambiente são entrelaçados e interdependentes, desenvolvidos em processos milenares de coevolução onde a vida foi adaptada a ecossistemas específicos (Maffi 2001). Tais relações deixaram materialidade e conhecimentos amplos e profundos sobre as espécies locais, relações ecológicas e funções dos ecossistemas, onde as pessoas aprenderam "como adaptar suas práticas culturais para se adequar aos seus nichos ecológicos" (Maffi 2001:4).

A ecologia histórica dos povos Tupí oferece a oportunidade para demonstrar o significado das palavras de Luisa Maffi. É uma história de longa duração registrada em dados linguísticos, arqueológicos, antropológicos, históricos e biológicos, que ajudam a compreender um processo iniciado cerca de cinco mil anos atrás por falantes do Proto-Tupí, matriz de 70 línguas historicamente conhecidas (Rodrigues e Cabral 2012). Os dados linguísticos e históricos convergem para os avanços da arqueologia amazônica dos últimos 20 anos, reforçando a necessidade de se avançar para uma teoria interdisciplinar unificada, incluindo aí simulações e modelagens computacionais (Riris 2018). As pesquisas arqueológicas na área da Cachoeira do Teotônio, inserida na região onde se desenvolveu o Proto-Tupí, revelam claras evidências da prática de manejo agroflorestal e consumo de mandioca, abóbora, feijões, frutas, sementes, tubérculos e raízes ao redor de 6 mil anos antes do presente (AP). A cerâmica Tupí mais antiga na área do Proto-Tupí foi datada em 4,5 mil AP, junto com terra preta antropogênica no sítio Encontro, próximo ao rio Ji-Paraná (Zimpel 2018).

Essas informações permitem explicar a persistência da estrutura de conhecimentos ambientais tradicionais Tupí. Vamos usar um modelo de "arqueologia reversa" (com princípios semelhantes aos da engenharia reversa, cf. Corrêa 2014), com marcadores preditivos e não-aleatórios localicazados e datados, com os dados do presente projetados para o passado (p.ex. Anthony 2010) definidos por uma pesrpectiva interdisciplinar (linguística histórica, arqueologia e etnografia da materialidade). Por exemplo, analisando as cerâmicas - um elo material de ligação do presente com o passado -, seria possível constatar que os "elementos comuns em determinados conjuntos cerâmicos no presente deveriam representar os elos mais antigos do ponto de 
vista da tradição tecnológica e, ao mesmo tempo, poderiam indicar relações culturais e linguísticas entre aqueles povos que os produziram" (Silva e Noelli 2017). Outros elementos do conhecimento ambiental tradicional podem ser usados, como fitólitos, polens e restos macro e micro botânicos. Igual valor seria atribuído aos aspectos intangíveis da cultura, especialmente os registros linguísticos.

Vamos abordar o caso de um destes povos, destacando as práticas que fundamentavam e estruturavam a gestão de recursos dentro do que chamamos de manejo territorial Guaraní (MTG), considerando que eram sistemáticas, planejadas e fundamentadas por uma vasta gama de conhecimentos, para prover segurança alimentar em ciclos anuais. Este trabalho apresenta um modelo dos aspectos estruturantes gerais do MTG, como revisão, atualização e ampliação da pesquisa de um dos autores deste artigo, realizada no período 1988-1993 (Noelli 1993).

Como objetivos específicos serão apresentados: i) conceitos Guaraní sobre as zonas vegetais definidos no começo do século XVII nos dicionários de Antonio Ruiz de Montoya (2011, 2002); ii) aspectos do modelo de policultura agroflorestal Guaraní.

O MTG tem origem na policultura agroflorestal desenvolvida na Amazônia, usando a linguagem, conceitos e fundamentos teóricos da estrutura de conhecimentos tradicionais comuns aos 70 povos falantes das línguas do tronco Tupí. Os ancestrais dos Guaraní levaram para fora da Amazônia um modelo agroflorestal e este artigo é a síntese dos aspectos mais relevantes para a compreensão deste padrão comportamental. Partimos do pressuposto que tais conceitos fundamentavam o MTG antes deles deixarem a Amazônia Meridional, de onde começaram a sair ao redor de 2,5 mil anos atrás para colonizar partes do Paraguai, Bolívia, Brasil, Argentina e Uruguai (Figura 1), alcançando um imenso espaço geográfico na Mata Atlântica e áreas de transição com os Biomas Cerrado, Chaquenho e Pampa (Brochado 1984; Bonomo et al. 2015). Os dados interdisciplinares mostram a prática de ocupar e manejar gradativamente o espaço conforme o crescimento demográfico, mantendo parte da população nos territórios antigos, enquanto outra parte transportava e manejava um pacote de plantas para novas áreas na periferia de seus locais de origem (Noelli 1993). Eles formavam o tekohá, uma unidade territorial com uma aldeia sede autônoma, autodeterminada e autossustentada. Aliavamse em redes de aldeias em proporções e escalas variáveis, mantendo contato permanente e trocando continuamente informações, coisas e pessoas. Tinham entre si diferenças dialetais, assim como variações sutis de organização política e social; contudo, compartilhavam uma estrutura de conhecimentos botânicos, zoológicos e ecológicos e um sistema tecnológico que produzia uma cultura material padronizada em suas nomenclaturas, morfologias e funções, com as 
matérias-primas variando conforme as ofertas locais e regionais. A soma dessas práticas provia segurança alimentar e fomentava as reservas estratégicas de matérias-primas.

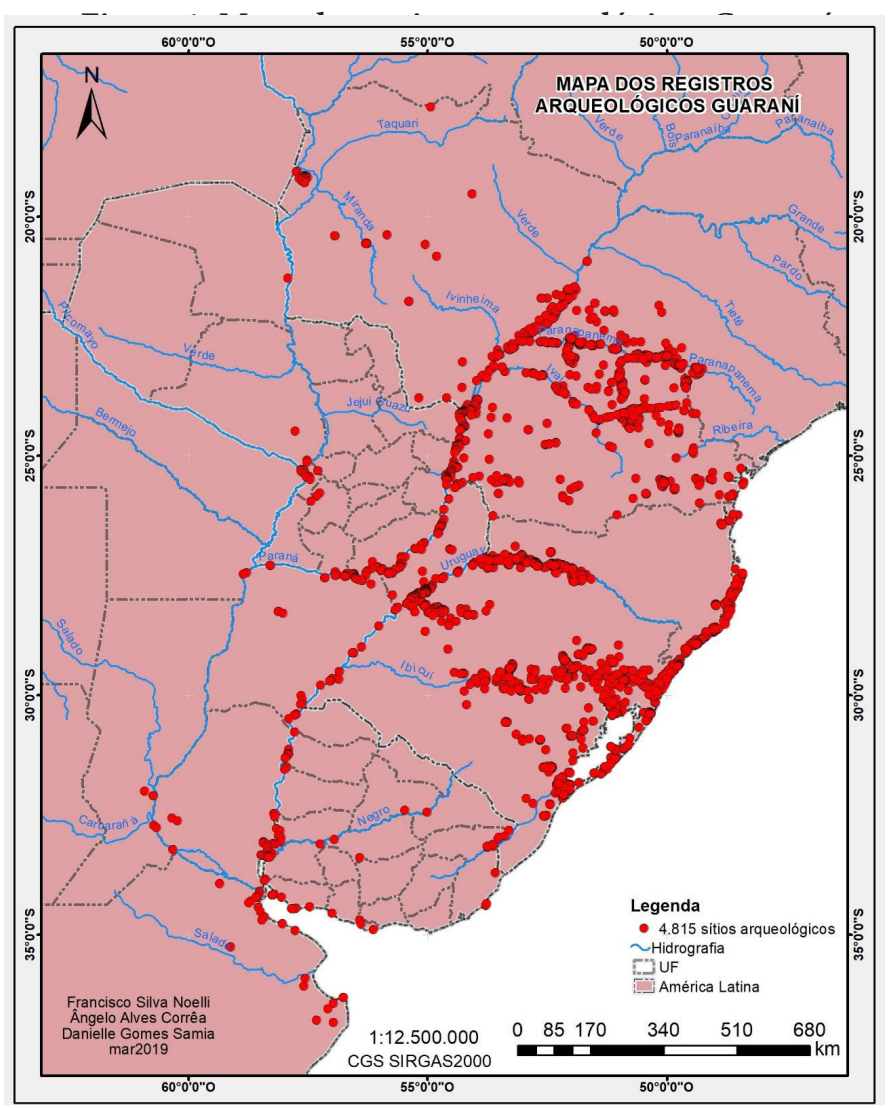

A noção de MTG é inspirada no conceito de "conhecimento etnobiológico tradicional" (Balée 2000), concebido considerando o tempo: tradição implica em antiguidade. Isto é, a tradição é devida ao acúmulo de experiências e conhecimentos transmitidos entre as gerações, às quais incluem mudanças e inovações. Balée (2013:123) sugere alguns princípios para o reconhecimento dos processos de transformação dos conhecimentos ambientais amazônicos: 1) o léxico de uma população indica o conhecimento da diversidade biótica de uma determinada região; 2) o conhecimento do meio-ambiente normalmente se restringe a contextos locais; 3 ) culturas e línguas codificam uma enorme quantidade de conhecimento verificável sobre o ambiente; 4) desde o período pré-colonial as paisagens foram transformadas por meio da redistribuição de espécies ao longo de regiões, enriquecendo contextos bióticos locais e regionais. Os Guaraní estruturam suas áreas de domínio a partir de tais princípios, mas há 
evidências de maior magnitude que o segundo princípio sugerido por Balée, uma vez que suas redes de aldeias formavam agrupamentos demograficamente muito maiores que os atualmente conhecidos pelos antropólogos, em escala pan-regional.

Os materiais que servem como base para investigar o MTG são os próprios sítios arqueológicos, as vasilhas e seus fragmentos, artefatos líticos e vestígios arqueobotânicos. Eles podem ser identificados nos registros linguísticos, históricos e etnográficos, uma vez que o léxico Guaraní nomeia artefatos e plantas resgatados dos contextos arqueológicos. A tarefa é cotejar e contextualizar esse universo empírico com informações etnográficas e históricas. O foco inicial de nossa análise está nos artefatos e plantas de diferentes lugares, e que possuem diversos exemplares registrados nas fontes escritas, nos museus e laboratórios de arqueologia e arqueobotânica, cuja comparação permite determinar as regularidades materiais e estabelecer os princípios para uma fitogeografia culturalmente influenciada ou construída.

\section{MTG como "nosso modo de ser"}

A comparação sistemática de dados arqueológicos, históricos, etnológicos, linguísticos e botânicos, mostra a cultura material produzida pelo ñande reko, traduzido como o "nosso modo de ser" (Melià, Grünberg e Grünberg 2008), o ethos cultural que balizava as práticas Guaraní. Ele define a identidade e a estratégia de conectar os grupos locais em redes regionais de relações políticas, sociais e econômicas. Pode ser traduzido como o sistema de transmissão de conhecimentos através de práticas educativas de uma geração à outra, de uma pessoa à outra no grupo doméstico e na comunidade local, para manter a continuidade e a regularidade das práticas, dos vocabulários, da taxonomia e da produção da cultura material (Wendrich 2012). O ñande reko é visível na cultura material, a exemplo da replicação das classes funcionais na cerâmica arqueológica, com elevada padronização tecnológica e morfológica, como se pôde verificar em 1936 vasilhas Guaraní de diversos sítios do Brasil, Paraguai, Argentina e Uruguai registradas e mensuradas por Noelli e Corrêa (s.d.).

A premissa que defendemos é a de que os Guaraní teriam uma estratégia cíclica para o MTG, cuja regra comum era seguir o ñande reko. É fundamental considerar que a produção de biomassa renovável para alimentação era estratégica como segurança alimentar, não sendo fortuita em condições normais, muito menos fruto da mera necessidade. Os dados indicam que vigoravam em seus assentamentos a prática estratégica de forrageio e policultura agroflorestal, adaptada às variações de cada ecossistema, operacionalizadas por um conjunto de artefatos replicados com características tecnológicas semelhantes. A diversidade paisagística e ambiental que eles ocuparam é ampla, indicando um 
modo de vida simultaneamente adaptável e adaptador dos contextos em que viviam. Os dados mostram que as sedes das suas aldeias ficavam próximas de fontes de água, em clareiras sob o estrato arbóreo, em solos diversificados dos mais pobres aos mais férteis, em altitudes que variavam entre o nível do mar e mais de 950 metros (Noelli 1999-2000, 2004; Corrêa 2014; Bonomo et al. 2015). Ocuparam inclusive o interior de matas de galerias, dentro de grandes capões de mata no campo, provavelmente contribuindo para a expansão da área dessas vegetações quando as condições locais de solo permitiam.

\section{MTG: transportando plantas, construindo um tekohá}

Consideramos a premissa que o MTG foi replicado em cada tekohá, a unidade de domínio territorial constituída pela aldeia sede, trilhas, áreas de policulturas agroflorestais e de pousio das roças/áreas de coleta, caça, pesca e outras áreas de atividades com estruturas menores de habitação e acampamento sazonal. Está claro que o MTG tinha por objetivo garantir a autossustentabilidade do grupo local tendo a policultura agroflorestal como base da alimentação, além do fornecimento de matérias-primas orgânicas e inorgânicas. Seus pilares são os conhecimentos geoambientais, ecológicos, astronômicos, climáticos, botânicos e zoológicos que orientavam a escolha dos ecossistemas para produzir o seu estilo de vida, aplicados para a exploração anual dos recursos naturais e inserção de um pacote de plantas que levavam consigo. Deve-se destacar que adotavam e multiplicavam as espécies locais que lhes eram úteis. Hector A. Keller (com. pessoal, fevereiro de 2019) sugere que os Guaraní, além de transportarem o tekohá para reproduzir suas etnoespécies, procuravam sucedâneos vegetais, um processo pelo qual a sua diversidade de recursos foi ampliada ao longo do tempo e no espaço, envolvendo adaptação de conhecimentos prévios à espécies sucedâneas (p. ex.: na Amazônia usariam uma espécie de Enterolobium Mart., para intoxicar peixes, enquanto que na Bacia Platina empregariam outra, mas do mesmo gênero botânico, Enterolobium cortortisiliquum (Vell.) Morong.); e o mesmo ocorreria no período colonial, com o ingresso de espécies sucedâneas introduzidas pelos europeus, como o rícino (Keller et al. 2018).

A estratégia do MTG era direcionada para manter os sistemas de organização social e de alianças com outras aldeias, alimentar as comunidades e suportar demandas variáveis de crescimento demográfico. Evidentemente, os Guaraní causavam impacto sobre os ecossistemas, mas os milhares de sítios arqueológicos e as informações históricas sugerem que o MTG e os seus sistemas formadores das florestas antropogênicas teriam potencial para ampliar a biodiversidade dos tekohás com plantas consideradas úteis, contribuindo para criar zonas com espécies diversificadas e zonas com espécies hiperdominantes, a exemplo do que ocorre na Amazônia (Ter Steege et al. 2013). 
A produção resultava da exploração concomitante das roças e áreas de coleta, podendo-se afirmar que, para os Guaraní, são corretas as conclusões de Lévi-Strauss (1950:465): 1) "existem muitos estágios intermediários entre a utilização de plantas em seu estado selvagem e seu verdadeiro cultivo"; 2) "agricultura sempre acompanha, e nunca é um substituto para a exploração de recursos selvagens". O modelo de policultura agroflorestal Guaraní é um balanço entre: 1) a produção sistêmica e preditiva para reproduzir anualmente um calendário agrícola; 2) a coleta sazonalmente distribuída ao longo do ano de várias espécies cultivadas e domesticadas em áreas diversas. No sentido de Rindos (1980) e Rival (1998:238), distinguimos cultivo de domesticação: cultivo é a atividade humana encorajando o crescimento de uma planta particular, enquanto domesticação implica em modificação morfológica e genética. Não sabemos se os Guaraní domesticaram as plantas que utilizavam, mas está claro que eles cultivavam em diversas zonas vegetais construídas por eles.

O quadro 1 mostra um modelo geral de impacto e formação de zonas vegetais ou paisagens etnoecológicas (Pirondo e Keller 2014), iniciando com a "mata virgem", passando por vários estágios de manejo ao longo de anos até o abandono definitivo (Noelli 1993). É importante considerar que a abundância de registros arqueológicos Guaraní indicam sua permanência em um mesmo território por centenas de anos e, em alguns casos, mais de mil anos (Bonomo et al. 2015). Essa longevidade cronológica poderia ter influenciado na fitossociologia das zonas vegetais por eles ocupadas.

Quadro 1: Modelo Geral do Impacto Guaraní sobre as Zonas Vegetais

vegetação natural $\rightarrow$ manejo $\backslash$ abandono $\rightarrow$ manejo $\backslash$ abandono... $\rightarrow$ vegetação cultural $\leftarrow$ tempo $\rightarrow$

introduçãoe manejo de pacotedeplantas $\rightarrow$ impacto nabiodiversidadevegetallocal $\backslash$ regional atração da fauna dispersora de sementes e polens em todas as etapas

O primeiro estágio é a implantação da roça nova em uma clareira aberta com derrubada e queima para introduzir o pacote de plantas alimentícias, medicinais e matéria-prima para confeccionar objetos. Nos estágios seguintes, com o passar do tempo, à medida que diminuía a fertilidade do solo, as roças eram transformadas em áreas de introdução de outras espécies úteis, ficando em pousio até a recuperação do solo. Nestas áreas de pousio eram cultivadas tanto as plantas de curto ciclo de maturação, quanto as arbóreas de longo ciclo para uso futuro. Estes locais também funcionavam como concentradores de "bagueiras" (espécies zoocóricas) atraindo animais e servindo como áreas de caça. O último estágio seria o abandono definitivo da área manejada, ficando com a composição transformada, o que garantia a ampliação da biodiversidade, 
notadamente as concentrações de espécies botânicas hiperdominantes (cf. Noelli 1993, p. ex.: araucária, erva mate, diversas arecáceas, taquaras, cedro, etc.).

A abertura de clareiras para a roça nova era anual, com uma parcela de tamanho variável destinada para cada família nuclear. A produção da roça nova era incrementada com a produção das roças mais antigas e das áreas de coleta. Portanto, a biomassa anual total de um tekohá resultava da soma de toda a produção agroflorestal de cada família nuclear, agrupadas por consanguinidade e sociabilidade em famílias extensas vivendo em uma casa grande chamada og (aportuguesada como oca). Dependendo da fertilidade dos solos e da disponibilidade de espaço, a produção anual total variava em cada assentamento (p. ex.: uma aldeia somaria a produção da roça nova mais a das roças de anos anteriores). Portanto, haveria disponibilidade de estoques de alimentos in natura et in situ, mais as plantas medicinais e matérias-primas para um abastecimento planejado e sustentável a cada ciclo anual.

As plantas são divididas em dois conjuntos principais (Noelli 1993; Pereira et al. 2016): 1) espécies mantidas e reproduzidas desde a Amazônia (p. ex.: mandioca, milho, cará, feijões, amendoim, abacaxi, maracujá, jenipapo); 2) espécies adquiridas e reproduzidas nas diversas áreas ocupadas sucessivamente à medida que se dirigiam ao sul (não avaliamos as espécies amazônicas perdidas por causas antrópicas ou naturais, como a barreira fitogeográfica de plantas como o caju, cuieira, castanha-do-Pará, açaí, etc.).

O outro pilar que garantia o MTG era a organização dos assentamentos em redes de aldeias interligadas politicamente. A carta geográfica dos sítios arqueológicos Guaraní mostra na figura 1 que não havia aldeias isoladas. Algumas parecem isoladas provavelmente devido à falta de levantamentos arqueológicos (Bonomo et al. 2015). Portanto, a comunicação e as mais diversificadas trocas humanas e materiais seriam constantes e permanentes. Materializava-se, assim, o ñande reko: o eixo que estruturava anualmente ações sociais, econômicas, políticas e cosmológicas, definidas por um calendário orientado pela astronomia, pela passagem das estações climáticas, pela floração de algumas espécies e pelo surgimento e nascimento de certos animais e insetos.

\section{MTG e o potirõ}

A instalação e a manutenção do tekohá resultavam de trabalho coletivo, do potirõ, um conceito Guaraní que define a cooperação, aportuguesado como "mutirão". A organização social baseada em famílias extensas residindo em um mesmo assentamento exigia colaboração e, segundo Melià (1989:318319), "para os Guaraní certas atividades são quase impensáveis se não são na forma de colaboração comum”. Sem colaboração era inviável viver como uma comunidade agroflorestal. Havia a necessidade de adequação aos ciclos 
climáticos para a derrubada e queima da mata, para o plantio, cuidado das roças, multiplicar e colher as plantas nas épocas corretas, manter desmatada a aldeia, as trilhas e outras áreas de atividade, construir uma canoa ou um pari (armadilha de pesca). Esses são alguns exemplos do potirõ, que abrangia a divisão do trabalho por gênero, a depender da tarefa. A pessoa convidada para uma destas tarefas sabia que na conclusão do trabalho haveria comida e cauim - bebida fermentada alcoólica - e, eventualmente uma festa (Noelli e Brochado 1998). E a pessoa sabia, quando chegasse sua vez de convidar, que teria a reciprocidade daqueles com quem colaborou.

A sede da aldeia era composta por uma ou mais casas, seus pátios e jardins de plantas úteis, instaladas em uma única clareira ou clareiras contíguas. Tais disposições podem ser verificadas nos sítios arqueológicos, muitos com ocupação longeva, incluindo a presença de solo antropogênico (sensu Schmidt 2013). Os tekohás eram entrecortados e conectados por trilhas que somariam centenas de quilômetros de caminhos na mata. O que obrigava a um contínuo trabalho de poda e limpeza da vegetação, sendo um exemplo de mutirão para terminar em festa, justamente por ser útil à comunidade. Um exemplo desse tipo de espacialidade foi descrita por Posey (1987), que estimou haver cerca de $500 \mathrm{~km}$ de trilhas entremeadas circundando uma aldeia Gorotire-Kayapó.

Na língua Guaraní há conceitos específicos para classificar e determinar as formações vegetais conforme as suas características mais gerais: campestre, alagadiça e florestal (para economizar espaço, as citações de Montoya são: T:378 = Montoya [1639] 2011:378; B: = Montoya [1640] 2002:87).

Nas áreas de vegetação campestre predominam as gramíneas e espécies rasteiras e arbustivas de pequeno porte. São definidas com o conceito de ñũ (prado, campo B:87, 328), também sendo espaço para caça, coleta e eventualmente cultivo, mas nunca para instalar aldeias. Define-se a vegetação de planície como "campo raso, ininterrupto" (ñururi T:378) ou "campo estendido, plano" (ñururi puku T:505). Existem definições de ecótonos para o encontro de áreas campestres e florestais, como ñuka'a vapy (princípio ou fim de campo vizinho ao mato T:73), bem como elementos de geomorfologia (p. e.: o ñu roguamby, "campo em encosta de morro" T:499).

Sobre a cobertura herbácea dos campos temos kapi'i poñỹ ("grama, capinzal" T:238, B:209). Conforme a concentração das gramíneas poderia ser um kapi'i týva ("ervaçal, campo com restevas" T:238, B:304) e um kapi'i tyvaíva ("capinzal espesso" B:304). Eram apreciados os capins do gênero Andropogon L., especialmente o aguara ruguái (Gatti 1985:11), para cobertura das habitações e outras estruturas. E havia interesse na relação do campo com o capão de mata, certamente um conceito indígena aportuguesado para definir a "ilha de mata ou ilha de árvores no campo" = ka'a pa'ũ (T:230, 398, B:240).

Com as informações históricas disponíveis, vemos que os Guaraní 
manejavam o capão de forma semelhante aos apêtê dos Gorotire-Kayapó (Posey 1987), transformando-os em verdadeiras ilhas de recursos através da inserção e concentração de plantas úteis (tal prática está dentro de um modelo amazônico que foi bastante comum em diversas regiões). Os campos dentro das áreas de mata: ka'a sãndo sãndog (T:507): "mata extensa com pedaços de campo". Em casos extremos é possível que através do manejo fosse ampliada a área dos capões de mato e das matas de galeria, permitindo até a inserção de um assentamento e roças no seu interior.

A floresta paludosa era definida como yapo ("pântano" T:631, 634). As porções sujeitas a alagamento ou que estavam constantemente cobertas por lâminas d'águas rasas tinham seus solos chamados como yvy nunu ("terra pantanosa" T:354). Eram os espaços para pesca e caça ao redor das lagoas e várzeas de rios, sendo inclusive áreas de coleta de diversas espécies de moluscos e plantas aquáticas e de áreas alagáveis.

Na língua Guaraní a vegetação florestal possui uma diversidade de conceitos que definem da mata "virgem" até os mais variados tipos de zonas vegetais continuamente modificados pela ação humana (Noelli 1998a). Tais conceitos (Tabela 1) e, provavelmente, o método, foram estabelecidos pelos falantes do Proto-Tupí ao redor de 5 mil anos atrás, conforme as reconstruções fonéticas da linguística histórica baseadas em 70 línguas das 10 famílias do tronco Tupí (Rodrigues e Cabral 2012). Os dados arqueológicos e centenas de datações de sítios arqueológicos (Corrêa 2017) dão suporte à antiguidade do Proto-Tupí. Os linguistas das mais diversas linhas teóricas aceitam que todas as línguas Tupí, especialmente a família Tupí-Guaraní, "sejam manifestações diferenciadas do que foi no passado uma mesma língua e que as propriedades compartilhadas sejam a herança comum conservada sem diferenciação ou apenas diferenciações menos profundas" (Rodrigues 1985:34).

A reconstrução fonética do léxico "roça" **yko (Rodrigues 2007, 2010), exemplifica parte da estrutura dos conhecimentos definidos quando os falantes do Proto-Tupí estabeleceram na Amazônia as práticas mais elementares da policultura agroflorestal. O levantamento da classificação Tupí de zonas vegetais que fizemos em fontes linguísticas, históricas e etnográficas de 39 línguas (Tabela 1), evidencia que o conceito foi mantido até o presente nas 10 famílias linguísticas. Também verificamos (Noelli 1993) que a roça nova era a unidade mínima de cultivo aberta anualmente por uma família nuclear, sendo o modelo padrão reproduzido com variações por todos os Tupí. A soma das unidades mínimas agrupadas em conglomerados vizinhos formados pela família extensa dentro de uma ou mais clareiras resultava na área total de roça anual. Evidências como fitólitos, grãos de pólen e restos macrobotânicos de plantas a serem identificados nos contextos arqueológicos provavelmente concordarão com os dados históricos e etnográficos, sendo outra possibilidade de comprovar a persistência do habitus agricultor Tupí por 50 séculos. 
Tabela 1: Alguns conceitos Tupí para zonas vegetais e tipos

\begin{tabular}{|c|c|c|c|c|c|}
\hline Língua & $\begin{array}{c}\text { Floresta } \\
\text { densa }\end{array}$ & $\begin{array}{l}\text { Roça } \\
\text { nova }\end{array}$ & $\begin{array}{c}\text { Roça vel- } \\
\text { ha (2-40 } \\
\text { anos) }\end{array}$ & $\begin{array}{c}\text { Descanso } \\
(40-+100 \\
\text { anos }) \\
\end{array}$ & Fonte \\
\hline Proto-Tupí & & ${ }^{* * 1}$ ko & & & Rodrigues 2007 \\
\hline Proto-Tupí-Guaraní & ${ }^{* n} \mathrm{Ka} \mathrm{Pa}$ & ${ }^{*}$ ko & & & Rodrigues 2007 \\
\hline \multicolumn{6}{|l|}{ Família Tupí-Guaraní } \\
\hline Guaraní & Kaá eté & Kog & Kokuéra & Kokuere ryma & Montoya 2011 \\
\hline Chiriguano & Kaaguasu & Ko & & & Giannecchini 1916 \\
\hline Sirionó & & Éko & Eko imã & Eko ke & Schermair 1957 \\
\hline Kaapor & Ka'a-te & Kupiša & Taperer & Taper & Balée 2013 \\
\hline Tapieté & Ka’awasu & & & & González 2005 \\
\hline Guaiá & Ka'a-ate & & & & Balée 2013 \\
\hline Tupínambá & Ka’a etẽ & Ko & Kôpuera & & Rodrigues 1966 \\
\hline Tenetehára & & Ko & & & Silva 2010 \\
\hline Zo'é & & Éko & Kopiaou & $\begin{array}{c}\text { Ekokuere\Ta- } \\
\text { per.et }\end{array}$ & Cabral 1996; Sousa 2013 \\
\hline Asurini do Xingu & Ka'a-ete & $\mathrm{Ka}$ & Kafera & & Balée 2013 \\
\hline Araweté & Kaã-hete & $\mathrm{Ka}$ & & & $\begin{array}{l}\text { Viveiros de Castro 1986; } \\
\text { Balée } 2013\end{array}$ \\
\hline Asurini do Trocará & Ka'a & Kopisa & & & Nicholson 1978.1982 \\
\hline Tembé & Ka'a-ete & Ko & & & $\begin{array}{l}\text { Rice 1934; Balée } \\
1994\end{array}$ \\
\hline Wirafed & & Ko & & & Nimuendaiú 1927 \\
\hline Kaiabi & Ka’a reté & Ko & $\begin{array}{c}\text { Kofet } \\
\text { rymaman }\end{array}$ & Kofet rarete & $\begin{array}{l}\text { Schmidt 2001; Stuchi } \\
2010\end{array}$ \\
\hline Parintintin & & Ko & Kopyahu & Komyan & Betts 1981 \\
\hline Parakanã & & $\mathrm{Ka}$ & & & Fausto 2001 \\
\hline Emérillon & & Eka & & & Grenand: Haxaire 1977 \\
\hline Wayampí & Ka'a ete & Koo & Kokue & & $\begin{array}{l}\text { Grenand; Haxaire } \\
\text { 1977: Jensen } 1989\end{array}$ \\
\hline Ava Canoeiro & & Ko & & & Borges 2006 \\
\hline Tapirapé & & $\mathrm{Ka}$ & & & Borges 2006 \\
\hline Kamayurá & & & Kohet & & Kamayurá 2012 \\
\hline \multicolumn{6}{|l|}{ Família Awetí } \\
\hline Aweti & Ka’a & Ko & Koput & & $\begin{array}{l}\text { Rodrigues 2007; } \\
\text { Kamayurá 2012 }\end{array}$ \\
\hline \multicolumn{6}{|l|}{ Família Mawé } \\
\hline Mawé & & Ko no & & & Rodrigues 2007 \\
\hline \multicolumn{6}{|l|}{ Família Jurúna } \\
\hline Jurúna & Ka'a & Kúá & & & Fargetti 2001 \\
\hline \multicolumn{6}{|l|}{ Família Munduruku } \\
\hline Munduruku & & Кә & & & Rodrigues 2007 \\
\hline Xipáya & & $\mathrm{Ku}-\mathrm{a}$ & & & Rodrigues 2007 \\
\hline Kuruáva & & $\mathrm{Ki}$ & & & Rodrigues 2007 \\
\hline \multicolumn{6}{|l|}{ Família Arikém } \\
\hline Arikém & & Nga & & & Rodrigues 2007 \\
\hline Karitiána & & $\mathrm{Na}$ & & & Rodrigues 2007 \\
\hline \multicolumn{6}{|l|}{ Família Tuparí } \\
\hline Makuráp & & Nge & & & Rodrigues 2007 \\
\hline Kepkiriwát & & Go & & & Rodrigues 2007 \\
\hline Wavoro & & $\mathrm{Ng} \varepsilon$ & & & Nogueira 2011 \\
\hline \multicolumn{6}{|l|}{ Família Mondé } \\
\hline Mondé & & $\mathrm{Ga}$ & & & Rodrigues 1966 \\
\hline Gavião & & $\mathrm{Ka}$ & & & Rodrigues 2007 \\
\hline PaitérZZoró & & $\mathrm{Na}$ & & & Rodrigues 2007 \\
\hline Cinta Larga & Kaa & $\mathrm{Ka}$ & & & Rodrigues 1966,2007 \\
\hline \multicolumn{6}{|l|}{ Família Ramaráma } \\
\hline Káro & & $\begin{array}{l}\text { Na-čéj, } \\
\mathrm{Na} \text {-čo }\end{array}$ & & & Rodrigues 2007 \\
\hline \multicolumn{6}{|l|}{ Família Puruborá } \\
\hline Puruborá & Gaté & Tá' & & & Koch-Grünberg 1932 \\
\hline
\end{tabular}


Os Guaraní tinham termos equivalentes à mata virgem, onde não havia indícios de ocupação humana e manejo da vegetação: ka'a marãne'ỹ (T:298): "mata de onde não se retirou madeira, nem foi cercado"; yvy marãne'ỹ (T:298): "solo intacto, que ainda não foi edificado" (T:648, yvy = "terra, solo, Orbe"; T:298, marãne' $\tilde{y}$ = "bom, inteiro, incorrupto, virgem"). Ali ocorriam atividades diversas, como caça, pesca, coleta e lazer, correspondendo a uma parcela considerável do tekohá que servia como reserva estratégica para futuras atividades agroflorestais, extração de matérias-primas, instalação de assentamentoslacampamentos, e como "zonas tampão" em relação aos vizinhos. Há um conceito para a mata pouco densa, talvez por causas naturais ou porque estava em alguma fase de regeneração pós-desmatamento: ka'a iñanãỹva'e (B:280): "mato ralo". Para as áreas de mata manejada há o conceito de ka'a katu (B:99): "mato claro" (com o sentido de mato bom, próprias para instalar roças e abrir caminhos), representando espaços com densidade naturalmente reduzida ou áreas com sucessão vegetal de roças em pousio, mais fáceis de serem limpas para futuros cultivos ou para instalar habitações, acampamentos, etc.

As áreas cultivadas são definidas como temytỹma (T:378), onde cresciam as temyty (Garcia 1985:73), as plantas da policultura agroflorestal manejadas continuamente a partir da Amazônia, além das espécies adotadas em cada uma das novas regiões conquistadas pelos Guaraní. O local da roça é definido como kog rupáva (T:254), "o lugar da roça”. A palavra kog (T:254; B:126) é o conceito de roça, ou roça nova. A roça nova denomina-se kog pyahu (T:254), enquanto as antigas, em estágios diversos de pousio, eram chamadas kokuéra (T:254): "roças velhas, já abandonadas"; e kokuere ryma (T:254): "roça muito antiga, já abandonada". Ao permanecer sem manejo ininterruptamente retornariam ao estágio de ka'a ete(T:230): "mata verdadeira, de paus grossos", as matas maduras com sinais de ação humana, as florestas antropogênicas representando o estágio com maior antiguidade na sucessão vegetal, distinta da ka'a marãne'ỹ. Uma descrição do início do século XVII ilustra o sistema Guaraní de derrubada, queima e cultivo para formar uma roça nova:

Esta nação é muito estendida e tem uma única língua; é gente agricultora, sempre planta nos matos e em cada três anos pelo menos mudam o local da roça. $\mathrm{O}$ modo de fazer suas semeaduras é: primeiro arrancam e cortam as árvores pequenas e depois as grandes e, perto da época de plantar, como as árvores pequenas estão secas (ainda que as grandes não estejam muito), lhes colocam fogo e se queima tudo que cortaram, e como o fogo é tão grande até as raízes acabamqueimadas. A terra limpa 
é fertilizada com a cinza e, no primeiro aguaceiro, é semeada com milho, mandioca e muitas outras raízes e legumes que eles têm muito bons..." (Lorenzana, [1620] 1951, p. 166).

A abertura de roças novas é um tema a ser investigado, que precisa considerar a fertilidade dos solos ao redor dos assentamentos. A citação acima menciona a abertura de roça nova a cada três anos, retratando as plantações nos solos mais férteis das missões jesuítas do Paraguai e da antiga província do Guairá. Nas áreas com solos menos férteis a abertura de roças novas seria anual, como ocorre na Amazônia e nas regiões de Mata Atlântica, especialmente na Planície Costeira. Mas é importante destacar que paralelamente eram mantidas as roças de anos anteriores para o cultivo de certas espécies, a exemplo das mandiocas, dioscóreas, feijões-de-corda e outras, incluindo frutíferas, medicinais e de matérias-primas. Nas áreas com menor fertilidade, deveriam usar a mesma estratégia dos Munduruku (Frikel 1959:7), aumentando proporcionalmente a área da roça em relação à área aberta em solos mais férteis.

A roça Guaraní é dividida em parcelas de cultivo, com unidades mínimas para cada família nuclear (ogpeguára B:195). O agrupamento por parentesco e afinidade destas famílias nucleares formava a família extensa, o te'ýi (T:578), que significa "parcialidade, genealogia" e coabitava uma casa grande (atualmente divididos em um conjunto de casas vizinhas) (Melià 2016:6569). Se a aldeia tivesse mais de um te'ýi, haveria número equivalente de roças e casas grandes. As roças vizinhas ou "continuadas", eram denominadas "kog jepota pota" (T:254). As áreas de cultivo eram divididas em parcelas familiares e as suas divisas chamavam-se kog yvyja (T:254): "limite da roça; o que está plantado no limite, que serve como cerca". O relato do missionário jesuíta Luis de la Roca no século XVIII resume o potirõ para abrir as parcelas da roça e como era planejada a derrubada da mata:

Para que naépoca defazer roça não se disperseagente, sejuntarão
com cada cacique os seus vassalos e todos farão juntos em um
dia a roça de alguém até termina-la e se for necessário mais dias
também; e depois todos juntos a roça de outro e assim as dos
demais vassalos de cada cacique (apud Garavaglia, 1987:155).

A área mínima de uma parcela é proporcional ao tamanho da família nuclear e o seu tamanho pode ser estimado a partir de alguns exemplos históricos de tamanho de área de roça nova documentados por diversos autores (Tabela 2): 
Tabela 2: Área média da roça nova Guaraní

\begin{tabular}{|l|l|l|l|}
\multicolumn{1}{c|}{ População } & \multicolumn{1}{c|}{ Quantidade } & \multicolumn{1}{c|}{ Área roça $\mathbf{~ m}^{\mathbf{2}}$} & \multicolumn{1}{c|}{ Fonte } \\
\hline Guaraní & 46 pessoas & c. 20.000 & Rengger, 2010:125 \\
\hline Guaraní Kaiová & Família nuclear & 5.000 a 20.000 & Watson, 1952:67 \\
\hline Guaraní & Família nuclear & 5.000 & Susnik, 1982:73 \\
\hline Guaraní Chiripá & Média 6 pessoas & c. 4.462 & Reed, 1999:151 \\
\hline Guaraní Paî-Tavyterã & Família nuclear & 5.000 a 20.000 & Melià et al., 2008:110 \\
\hline
\end{tabular}

A área varia entre os tamanhos médios mínimo de $5.000 \mathrm{~m}^{2}$ e máximo de $20.000 \mathrm{~m}^{2}$. Se uma aldeia possuía em um determinado momento 60 famílias, cada uma com uma roça nova de $5.000 \mathrm{~m}^{2}$, então a área total aberta anualmente seria de aproximadamente $300.000 \mathrm{~m}^{2}$ ou 30 hectares. Se a média possui roças com $20.000 \mathrm{~m}^{2}$, então a soma será $1.200 .000 \mathrm{~m}^{2}$ ou 120 hectares abertos anualmente. Em 10 anos estima-se que uma aldeia com 60 famílias cultivou um espaço médio mínimo de 300 hectares e um máximo de 1.200 hectares de roças novas.

É necessário acrescentar o volume da produção de biomassa das roças antigas e das áreas de coleta de cada família nuclear. É uma equação com variáveis que precisa ser desenvolvida para estimar a produção total anual de um tekohá, considerando que todas as roças de cada família nuclear poderiam ter tamanhos mínimos e máximos constantes. Deve-se considerar que a produtividade das roças antigas diminuiria por causa da redução da fertilidade dos solos mas, simultaneamente, outras espécies seriam produzidas, como as frutíferas e outras espécies alimentícias. Em áreas com solos menos férteis, pode-se estimar que em dez anos cada família nuclear teria um mínimo de dez áreas distintas, com uma roça nova e nove antigas produzindo paralelamente alimentos, medicinais e matérias-primas. Com outras possibilidades, para áreas com solos mais férteis, poderia haver um número menor de roças novas, que seriam abertas a cada dois ou três anos, como no relato acima do missionário jesuíta Marciel de Lorenzana, diminuindo pela metade ou em um terço a área agrícola total em dez anos. Mas é provável que a produtividade total fosse semelhante em ambos os tipos de solos, senão os Guaraní também fariam roças anuais sobre os solos férteis. A diferença seria uma quantidade menor de horas de desmatamento nas roças dos solos mais férteis, mas deveria haver mais horas de manutenção para conter o rebrote das plantas invasoras.

Ainda existe o problema da demografia e suas variáveis locais por resolver, tema totalmente aberto às novas investigações, especialmente a consideração da existência de famílias poligâmicas e da produção de excedentes para os diversos potirõ, festas e rituais, fatores que levavam ao aumento do tamanho da área das roças. O importante é que os números acima oferecem pontos 
de partida, referências mínimas e máximas para investigar simultaneamente áreas de desmatamento e repovoamento de plantas diversas, selecionadas por suas funções alimentares, medicinais e para elaborar artefatos.

Também cultivavam frutíferas e medicinais ao redor das habitações (Noelli 1993; Reed 1999:132). A estimativa do volume de tais produções em relação à área aberta para cultivo ainda não foi realizada, mas é tema que pode ser investigado nas comunidades atuais. As trilhas possuem grande potencial para cultivos diversos, mas permanece um tema inédito para os Guaraní. Seria importante seguir o exemplo de Posey (1987:177), que quantificou as plantas manejadas em um caminho de $3 \mathrm{~km}$ por 2,5m de largura média: 185 frutíferas, 1.500 plantas medicinais, 5.000 tuberosas alimentícias de várias espécies. As trilhas serviam para receber mudas de espécies úteis encontradas no interior da mata durante caçadas e outras incursões, para posterior transplante nas roças. $\mathrm{O}$ ato de transplantar era importante para os Guaraní, definido como ejýi, ayvyra ejýi (T:118, 653), prática embasada por conhecimentos que garantiam a multiplicação de plantas úteis, trazidas de nichos naturais e outras aldeias.

As áreas de "pousio" kog pe'iháva (T:254) poderiam ser cultivadas até chegar ao estágio de comunidades com uma espécie dominante, onde eram intensificadas as atividades de coleta. Por exemplo, a inclusão do sufixo tyva ao nome da planta significa concentração, abundância. Nas antigas roças haveria concentrações de frutíferas diversas: yva'ytýva (T:645 "arvoredo frutífero"), como os jaboticabais, palmeirais e os cultivos de abius, canelas, ocoteas e, no período missioneiro, da erva mate, etc. Havia, os kuri'y týva de Araucaria angustifolia (Bertol.) Kuntze (T:281, kuri'y = "pinhão"); os pindo týva, palmeirais de pindo (Syagrus romanzoffiana (Cham.) Glassman, $\mathrm{T}: 417$ ), úteis como alimento (fruto), folhas para cobertura, caule para artefatos (arcos, pontas de flecha, etc.). As palmeiras, após derrubadas ou tombar naturalmente, geravam alimento com proteína de alta qualidade nos troncos apodrecidos (Vera e Brand 2012), com a proliferação de besouros e gorgulhos (p. ex.: Rhinostomus barbirostris e Rhynchophorus palmarum), que poderiam produzir até $5 \mathrm{~kg}$ de larvas por metro de tronco (Miraglia 1975); outras espécies poderiam conter cerca de 300 larvas em um determinado pedaço do tronco (Strelnikov 1928:346). Os taquarais - takua týva (T:525; Guadua spp., Chusquea spp., Merostachys spp.) - eram importantes e provavelmente foram manejados, pois além de fornecer matéria-prima são criadouros de larvas de várias espécies de borboletas da família Phaloenidae (Strelnikov 1928:346). O quadro 2 esquematiza as Zonas Vegetais Guaraní, aplicando-se o modelo da figura 1: 


\section{Quadro 2: Modelo de Zonas Vegetais Guaraní}

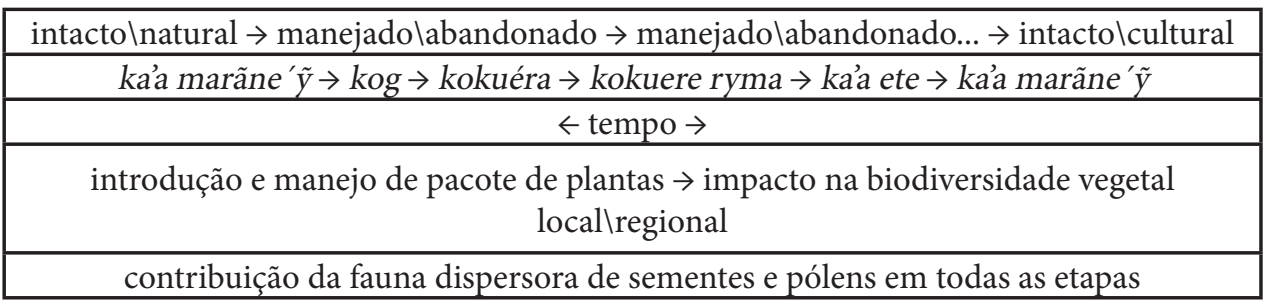

\section{MTG: as plantas manejadas pelos guaraní}

As plantas manejadas podem ser agrupadas em dois conjuntos: 1) conhecidas; 2) utilizadas. Evidentemente tinham utilidade porque eram conhecidas e definidas nominalmente, mas nem todas conhecidas foram utilizadas. Consideramos aqui somente os usos e conhecimentos Guaraní, que em várias espécies são distintos daqueles reconhecidos pela Botânica.

A metodologia é restrita ao levantamento botânico de dados na bibliografia etnográfica e histórica Guaraní, realizado por pesquisadores no século XX (cf. Fiebrig-Gertz, 1932; Cadogan, 1955; Martínez-Crovetto, 1968a, 1968b, 1968c; Arenas; Moreno-Azorero, 1976; Perasso; Vera, 1988; Noelli, 1993, 1994, 1998a, 1998b, 1998c; Muller, 1997; Keller, 2003, 2008, 2009a, 2009b, 2010a, 2010b, 2010c, 2010d, 2011a, 2011b, 2012, 2013; Bueno, 2005; Oliveira, 2009; Balée; Cebolla Badie, 2009; Dujak; Marchi, 2010; Keller; Prance, 2008, 2012; Keller; Crockett, 2015; Keller; Torres; Prance, 2011; Keller; Pirondo; Stampella, 2018; Keller et al., 2010, 2015; Pirondo; Keller, 2014; Pirondo et al., 2018). A maioria deixou material em herbários da Argentina, Paraguai, Brasil e outros países, que não foram usados aqui. O objetivo preliminar é formar um banco de dados bibliográficos para listar espécies conhecidas ou utilizadas, reafirmando o uso Guaraní, para posteriormente ter uma base para futuras pesquisas nos herbários e em campo entre os Guaraní. A verificação, correção e atualização dos dados foi pela comparação entre as taxonomias da bibliografia Guaraní com as bases atuais, como o GBILF, REFLORA e a bibliografia. O banco soma atualmente 1.207 espécies, divididas em 140 famílias, em grandes grupos de plantas (Fig. 2): 117 angiospermas (Angiosperm Phylogeny Group - APG IV, 2016), 19 samambaias/licófitas (Smith et al. 2006), 3 gimnospermas (BFG 2015) e 1 briófita (Crandall-Stotler et al. 2009). Deste total, 22 foram identificadas como exóticas, configurando adoção de espécies trazidas para as Américas após a chegada dos europeus. Mas devido às lacunas nas fontes, 73 ainda não foram identificadas com nome Guaraní, apesar da existência da indicação sobre seu uso e/ou conhecimento. 
Figura 2: Divisão Taxonômica das 140 famílias.

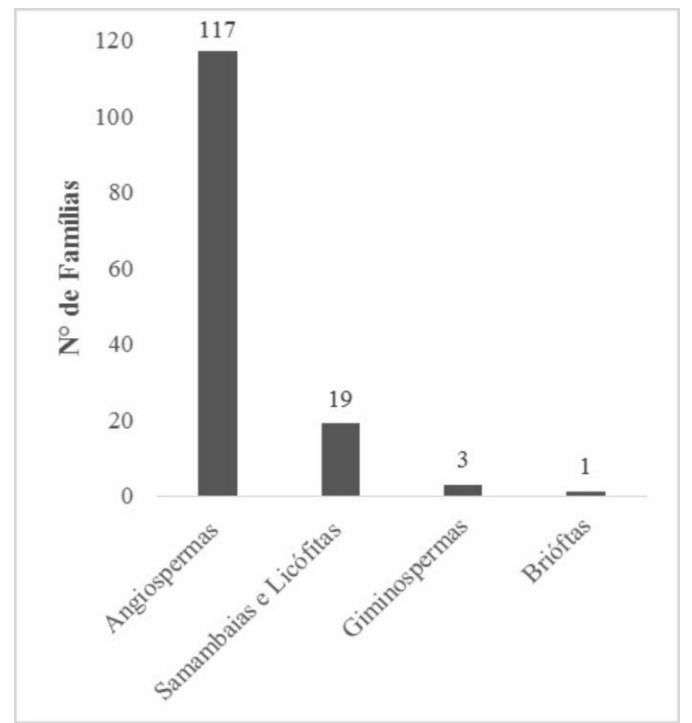

A maioria $(54,2 \%)$ das 140 famílias possui entre 4 e 131 espécies de plantas, enquanto que as famílias que possuem de 1 a 3 espécies compreendem $45,7 \%$ do total (Fig. 3). Como exemplo, destacamos algumas com mais de 20 espécies: Fabaceae (131); Asteraceae (74); Myrtaceae (67); Poaceae (60); Rubiaceae (39); Solanaceae (35); Malvaceae (31); Bignoniaceae (30); Lauraceae (27); Sapindaceae (25); Apiaceae (20).

As espécies serviam para usos diversos, divididos em 10 itens (Fig. 4): medicinal (Me); alimentar (Al); ritual (Re); artefato (Ar); construção (Cot); tóxico (Tox); higiene pessoal (HP); curtume $(\mathrm{Cu})$; bioindicador $(\mathrm{BI})$; sem indicação (SI). Estes itens foram definidos para incluir os usos pré-coloniais (Noelli, 1993) e pós-coloniais (Oliveira 2009), incluindo-se os usos comerciais do presente. $\mathrm{O}$ item medicinal compreende o maior número proporcional, com 371 espécies. As alimentares possuem elevado número, mostrando a sua relevância com 359 espécies. Sete itens podem ser incluídos nas matériasprimas para produção de cultura material, com 528 espécies. Uma parte das 247 espécies rituais poderiam ser acrescentadas na cultura material, alterando o resultado final. As bioindicadoras somam 5 espécies, sendo tema de investigação por desenvolver, pois os Guaraní, além dos usos analisados, por exemplo, possuem uma taxonomia com inúmeras designações para "planta de animal" (consumidas pela fauna). Não encontramos indicações de uso para 195 espécies, apesar de 192 terem nomes Guaraní; portanto, eram conhecidas e, provavelmente, usadas. 
Figura 3: Famílias que possuem entre 1 e 131 espécies

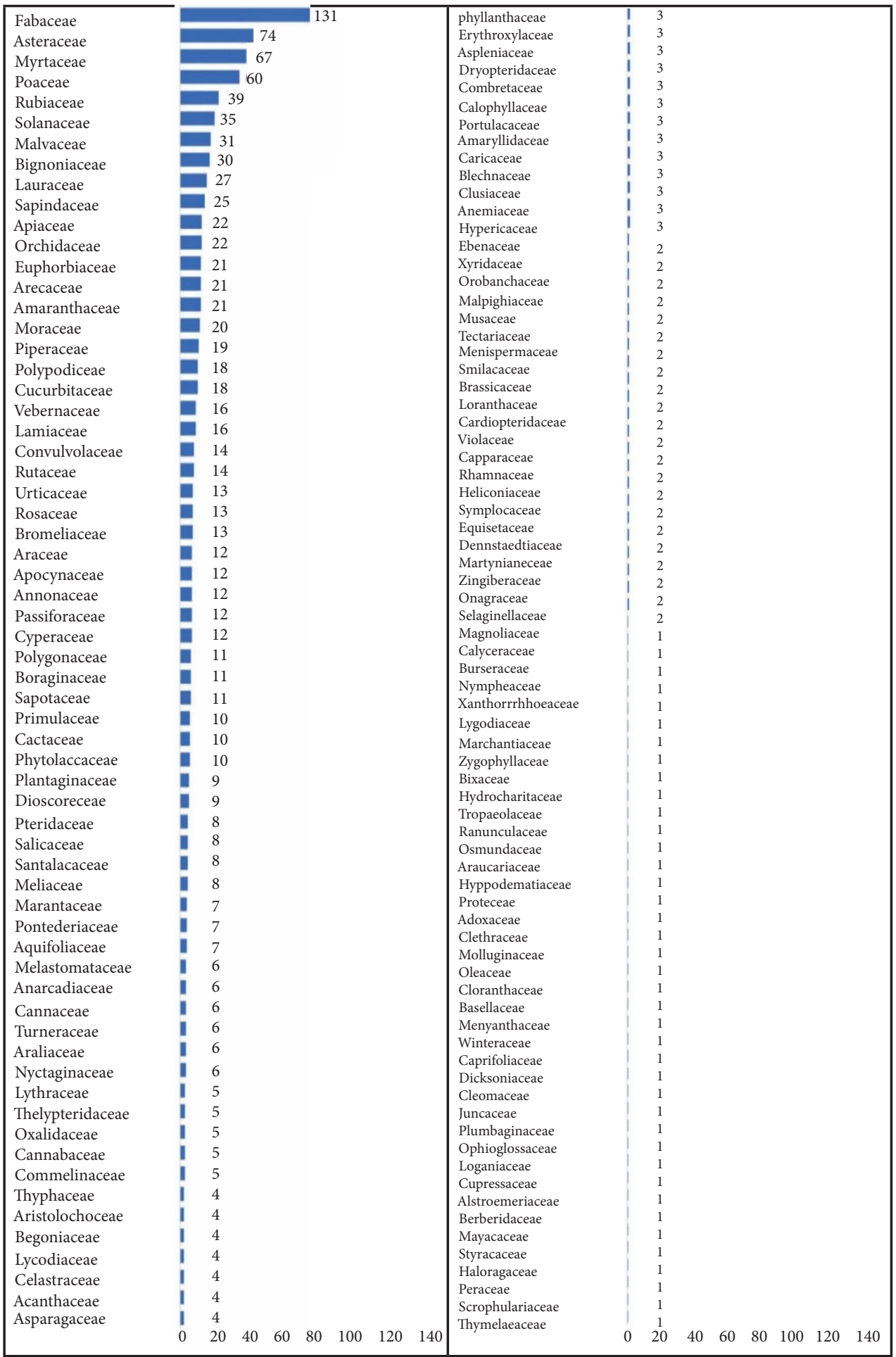


Figura4: Levantamento etnográfico dos usos das plantas

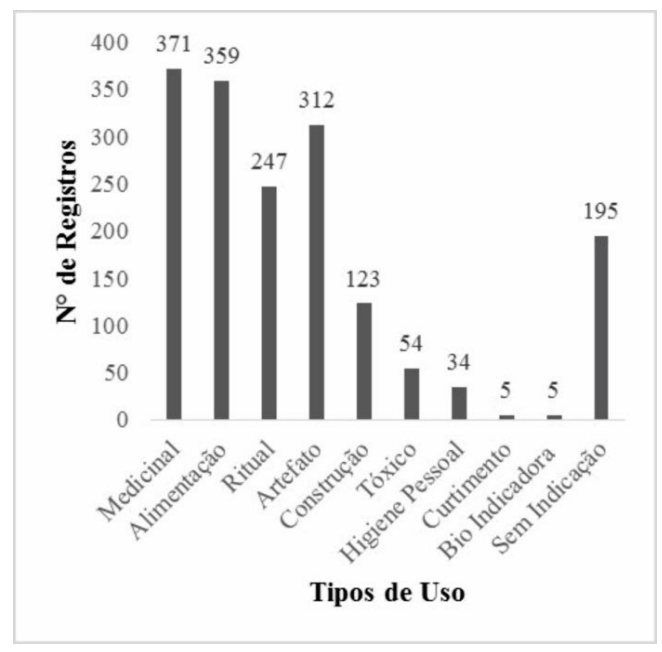

A investigação sobre o uso das plantas identificou as partes utilizadas (Fig. 5), revelando alguns aspectos do conhecimento tradicional na alimentação, medicina e produção de objetos. Contudo, há um número elevado de lacunas nas fontes no que diz respeito a quais seriam as partes utilizadas de 441 espécies vegetais.

Figura 5: Partes das plantas utilizadas pelos Guaraní

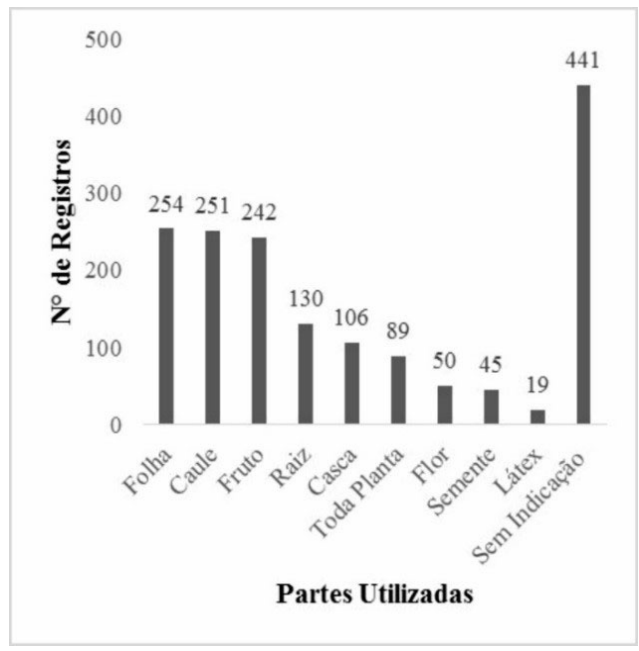

Aanálise mostra que o conhecimento tradicional resultou em usos variados das partes de cada planta em cada família botânica. Das 140 famílias, selecionamos 6 para apresentar os tipos de usos baseados em conhecimentos transmitidos entre as gerações, tema a ser desenvolvido com estudos comparativos entre as populações que compõem a família Tupí-Guaraní (e seria importante estender a comparação para as demais 9 famílias do tronco Tupí). O objetivo futuro é 
verificar como a extensão dos conhecimentos botânicos tradicionais ultrapassa o nível local, como sugere Balée (2013).

\section{Fabaceae}

Os usos de Fabáceas para a produção de objetos e cultura material predominam com $52 \%$ do total (artefato $23 \%$; construção $9 \%$; ritual $18 \%$; tóxicos $8 \%$ e higiene $1 \%$ ). Alimentação corresponde a $11 \%$ e as medicinais a $14 \%$, enquanto que ainda $15 \%$ estão sem informação de uso (Fig. 6).

Figura 6: Faabaceae e seus usos

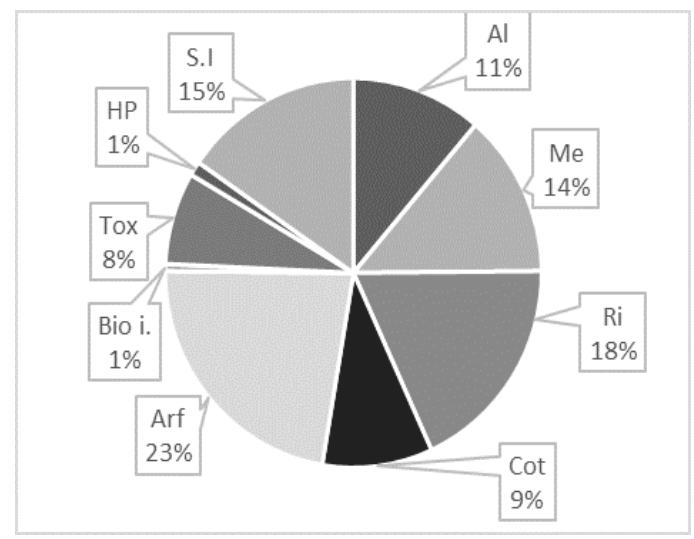

\section{Asteraceae}

As Asteraceae medicinais correspondem a 39\%, as alimentares a $7 \%$, enquanto que as sem informação de uso somam $11 \%$. Os usos relativos à produção de objetos e cultura material predominam totalizando $43 \%$ (artefato $8 \%$; construção $1 \%$; ritual $27 \%$; tóxicos $5 \%$ e higiene $2 \%$ ). Considerando que a quantidade de rituais e medicinais somam $66 \%$, as Asteraceae possuem grande importância para os Guarani, necessitando de investigações adicionais (Fig. 7).

Figura 7: Asteraceae e seus usos

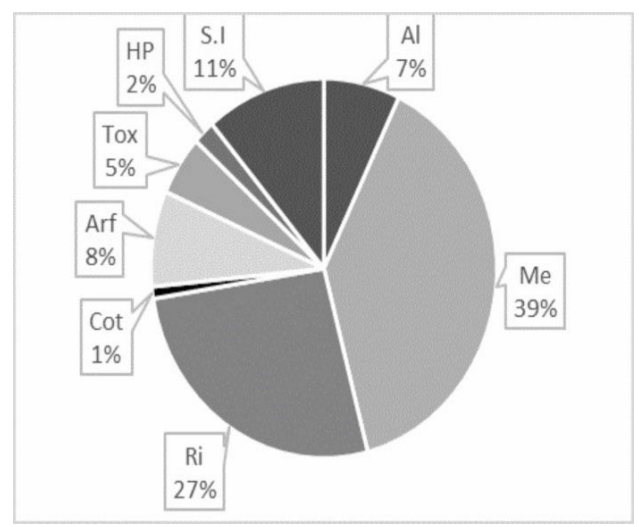




\section{Myrtaceae}

O uso das Myrtaceae como alimento corresponde a $69 \%$, enquanto a cultura material alcança $18 \%$ e as medicinais $9 \%$. As sem informação de uso são $4 \%$, mostrando ser uma família bem documentada (Fig. 8).

Figura 8: Myrtaceaae e seus usos

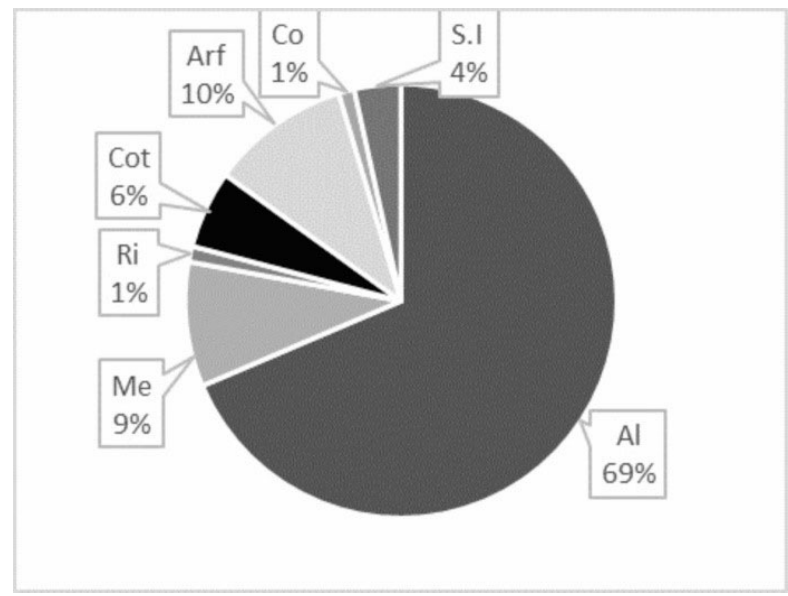

\section{Poaceae}

A produção de artefatos destaca-se entre as Poaceae, com 58\% divididos entre construção (24\%), artefatos (27\%), higiene (4\%) e ritual (4\%). As medicinais são $15 \%$, as alimentares $7 \%$ e as bioindicadoras $1 \%$, enquanto que as sem informação de uso chegam a 17\%. A família se destaca especialmente como matéria-prima, mas o milho (Zea mays L.) é uma das espécies alimentares mais destacadas entre as utilizadas pelos Guaraní (Fig. 9).

Figura 9: Poaceae e seus usos

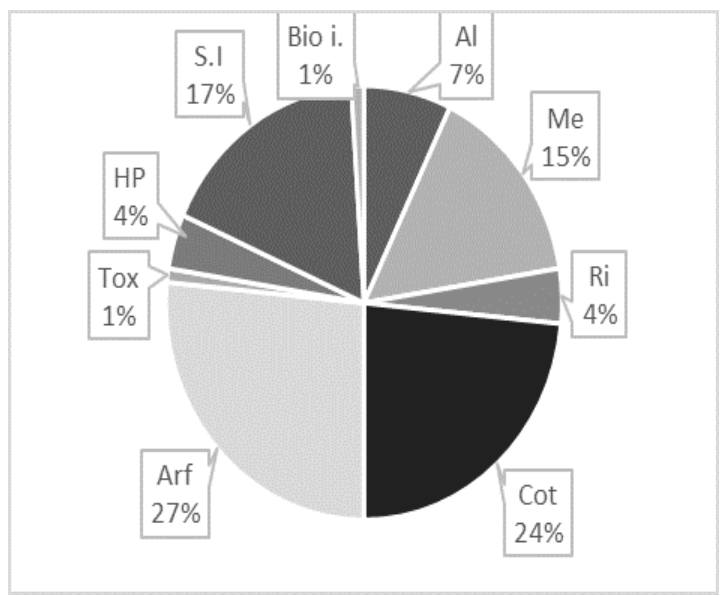




\section{Rubiaceae}

Os usos simbólicos e para produzir cultura material se destacam entre as Rubiaceae, com $35 \%$ para rituais e $31 \%$ para matérias-primas. As medicinais somam $15 \%$, as alimentares apenas $4 \%$ e as sem informação de uso $15 \%$ (Fig. $10)$.

Figura 10: Rubiaceae seus usos

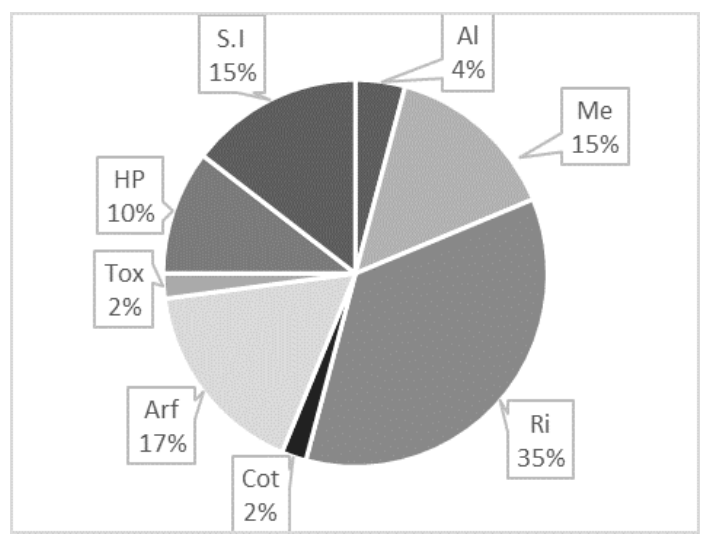

\section{Arecaceae}

As palmeiras possuem grande importância para a cultura material com $63 \%$, dividida em artefatos (28\%), construção (19\%), ritual (4\%) e higiene (2\%). A alimentação perfaz $25 \%$ e as medicinais $11 \%$, com $11 \%$ sem informação de uso (Fig. 11).

Figura 11: Areacaceae seus usos

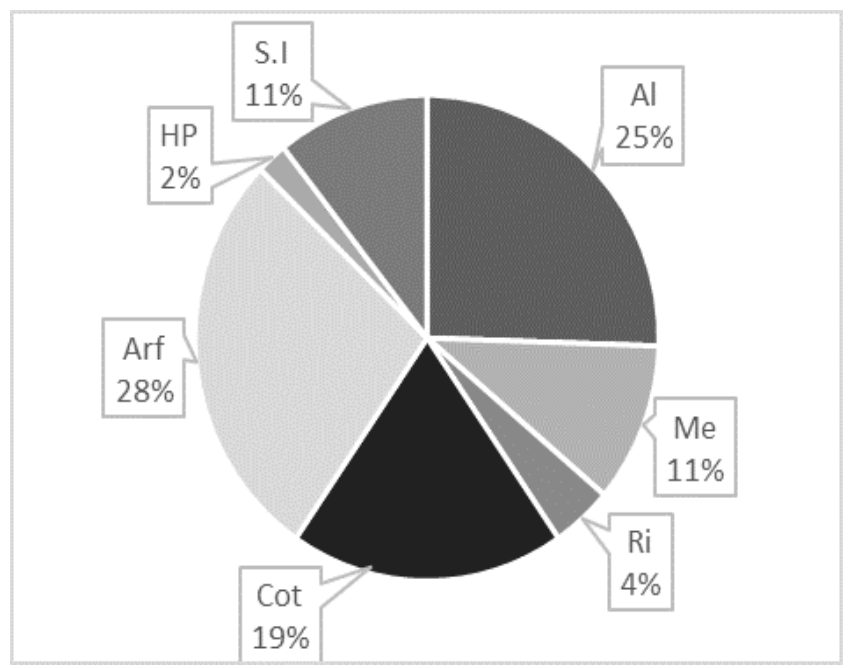


A tabela 3 mostra as plantas alimentícias mais comuns manejadas pelos Guaraní (Noelli 1994). A maioria provavelmente deve ter origem amazônica e outras, incluindo as sucedâneas, podem ter sido incluídas posteriormente em outros biomas ao longo da expansão rumo às regiões meridionais do Brasil e partes da Bolívia, Paraguai, Argentina e Uruguai. Durante este longo processo houve trocas de plantas entre essas regiões, sendo uma explicação para a presença de espécies oriundas em biomas onde elas não existiriam naturalmente.

Tabela 3: Alguns alimentos da roça Guaraní

\begin{tabular}{|c|c|c|c|c|}
\hline & Nome Popular & Nome Guaraní & Nome científico & $\begin{array}{c}\mathrm{N}^{\circ} \text { de } \\
\text { cultivares }\end{array}$ \\
\hline \multirow[t]{3}{*}{ Tuberosas } & \begin{tabular}{|l} 
Mandioca \\
Batata doce
\end{tabular} & $\begin{array}{l}\text { Mandio } \\
\text { Jety }\end{array}$ & $\begin{array}{l}\text { Manihot esculenta } \\
\text { Ipomoea batatas }\end{array}$ & $\begin{array}{l}24 \\
21 \\
\end{array}$ \\
\hline & $\begin{array}{l}\text { Batata "inglesa" } \\
\text { Cará } \\
\text { Feijão macuco }\end{array}$ & $\begin{array}{l}\text { Maky } \\
\text { Kara } \\
\text { Mbakuku }\end{array}$ & $\begin{array}{l}\text { Solanum tuberosum } \\
\text { Dioscorea spp. } \\
\text { Pachyrrhizus erosus }\end{array}$ & $\begin{array}{l}1 \\
9 \\
3\end{array}$ \\
\hline & $\begin{array}{l}\text { Mangarito } \\
\text { Araruta } \\
\text { Batatinha }\end{array}$ & $\begin{array}{l}\text { Tajao } \\
\text { Akuti } \\
\text { Makyxi }\end{array}$ & $\begin{array}{l}\text { Xanthosoma sagitifolium } \\
\text { Maranta arundinacea } \\
\text { Oxalis sp. }\end{array}$ & $\begin{array}{l}2 \\
1 \\
4\end{array}$ \\
\hline \multirow[t]{4}{*}{ Graníferas } & $\begin{array}{l}\text { Piriquiti } \\
\text { Milho } \\
\text { Feijões } \\
\end{array}$ & $\begin{array}{l}\text { Mbery sa'yu } \\
\text { Avati } \\
\text { Kumanda }\end{array}$ & $\begin{array}{l}\text { Canna glauca } \\
\text { Zea mays } \\
\text { Phaseolus spp. } \\
\end{array}$ & $\begin{array}{c}1 \\
13 \\
16 \\
\end{array}$ \\
\hline & $\begin{array}{l}\text { Amaranto } \\
\text { Quinoa } \\
\text { Amendoim }\end{array}$ & $\begin{array}{l}\text { Ka’aruru } \\
\text { Ka’are } \\
\text { Manduvi }\end{array}$ & $\begin{array}{l}\text { Amaranthus sp. } \\
\text { Chenopodium sp. } \\
\text { Arachis hypogaea }\end{array}$ & $\begin{array}{l}4 \\
? \\
7\end{array}$ \\
\hline & $\begin{array}{l}\text { Tremoceiro } \\
\text { Feijão guandu } \\
\text { Feijões }\end{array}$ & $\begin{array}{l}\text { Manduvirá } \\
\text { Kumanda Yvyra’i } \\
\text { Kumanda cha’i } \\
\text { Kumanda Ete } \\
\end{array}$ & $\begin{array}{l}\text { Lupinus sp. } \\
\text { Cajanus cajan. } \\
\text { Strophostyles sp. } \\
\text { Vigna Phaseolus spp } \\
\end{array}$ & $\begin{array}{l}? \\
? \\
? \\
?\end{array}$ \\
\hline & \begin{tabular}{|l|} 
Fava de rama \\
Algarrobo \\
Urucum \\
\end{tabular} & \begin{tabular}{|l|} 
Kumanda usu \\
Yvope \\
Uruku \\
\end{tabular} & \begin{tabular}{|l|} 
Canavalia sp. \\
Gleditschia amorphoides \\
Bixa orellana \\
\end{tabular} & $\begin{array}{l}? \\
1 \\
1 \\
\end{array}$ \\
\hline \multirow[t]{3}{*}{ Cucurbitáceas } & Abóbora cheirosa & Andai & Cucurbita moschata & 4 \\
\hline & $\begin{array}{l}\text { Moranga } \\
? \\
?\end{array}$ & $\begin{array}{l}\text { KurapepêTum- } \\
\text { byky } \\
\text { Guati áí }\end{array}$ & $\begin{array}{l}\text { Cucurbita máxima } \\
? \\
?\end{array}$ & $\begin{array}{l}1 \\
? \\
?\end{array}$ \\
\hline & Cruá & Kurugua & Sicana odorifera & 1 \\
\hline \multirow[t]{8}{*}{ Frutíferas } & Abacaxi & Nanã & Ananas bracteatus & $?$ \\
\hline & Goiaba & Arasa & Psidium guajava & 7 \\
\hline & Maracujá & Mburukuja & \begin{tabular}{|l|} 
Passiflora spp. \\
\end{tabular} & 11 \\
\hline & Genipapo & Ñandipáva & Genipa americana & 1 \\
\hline & \begin{tabular}{|l|} 
Pitanga \\
\end{tabular} & Yva pytã & \begin{tabular}{|l|} 
Eugenia uniflora \\
\end{tabular} & 1 \\
\hline & & Yvahái & Eugenia sp. & 7 \\
\hline & Jaboticaba & Yvaporu & Plinia sp. & 2 \\
\hline & Guabiroba & Guavira & Campomanesia sp. & 3 \\
\hline
\end{tabular}




\begin{tabular}{|c|c|c|c|c|}
\hline \multirow[t]{16}{*}{ Frutíferas } & Araticum & Aratiku & Annona spp. & 3 \\
\hline & Abiu & Agua'i & Chrysophyllum sp. & 4 \\
\hline & & Agua’i & Pouteria spp. & \\
\hline & Ingá & Inga & Inga spp. & 5 \\
\hline & Embaúva & Amba’y & Cecropia sp. & 1 \\
\hline & Tarumã & Taruma & Vitex megapotamica & 1 \\
\hline & Costela de Adão & Guembepy & Monstera deliciosa & 1 \\
\hline & Jacaratia & Jakaratia & Jacaratia spinosa & 1 \\
\hline & Bocaiúva & Mbokaja & Acrocomia aculeata & 1 \\
\hline & Indaiá & Pindo andaí & Attalea sp. & 1 \\
\hline & Tucum & Karanda’y & Bactris spp. & 1 \\
\hline & Butiá & Jata'i & Butia spp. & 4 \\
\hline & Palmito Jussara & Jujy & Euterpe edulis & 1 \\
\hline & Guaricana & Pindo'í & Geonoma spp. & 1 \\
\hline & & Taytetu ka’a & Spathicarpa sp. & 1 \\
\hline & Jerivá & Pindo & Syagrus romanzofiana & 1 \\
\hline
\end{tabular}

\section{Micofagia}

$\mathrm{O}$ consumo de fungos era comum e constante como fonte alternativa de proteínas, vitaminas minerais e fibras, genericamente chamados como urupe, sendo outro tema inteiramente aberto à investigação. Na área circunvizinha ao norte do sítio arqueológico Guaraní do Arroio do Conde, localizado ao norte do Lago Guaíba, no Rio Grande do Sul, foram identificados pelo menos 49 espécies comestíveis, com fenologia distribuída ao longo do ano, com maior oferta nos meses mais quentes (Quadro 03, cf. Pereira, 1984, 1988, 1990, sistematizado por Noelli, 1993):

Quadro 03: Oferta mensal de fungos no tekohá do Arroio do Conde.

\begin{tabular}{|c|c|c|c|c|c|c|c|c|c|c|c|c|}
\hline Mês & Jan & Fev & Mar & Abr & Maio & Jun & Jul & Ago & Set & Out & Nov & Dez \\
\hline Espécies & 15 & 16 & 40 & 36 & 31 & 30 & 15 & 7 & 9 & 10 & 11 & 10 \\
\hline
\end{tabular}

Dados históricos mostram a importância dos fungos como alimento. Um relato de 1639 retratou a coleta e o consumo de fungos pelos Guaraní:

\footnotetext{
"se foram por aquele mato, e ao cabo de muito pouco voltaram com a comida. Traziam um bom envoltório de fungos numas folhas grandes e, juntamente, traziam umas raízes de árvores bem grandes, que pareciam na cor e feitura com nabos... Os fungos envoltos em folhas foram metidos na brasa encoberta pelas cinzas." (Montoya, 1989, p. 144).
}

\section{Conclusão}

Este artigo mostrou aspectos gerais de um modelo sobre o conhecimento ambiental tradicional Guaraní. Se fosse possível resumir a uma expressão reduzida, diríamos que o processo coevolucionário entre ambiente e cultura 
moldou as regras mínimas do MTG Guaraní, legando-lhes conhecimentos e práticas para viver no interior da mata, explorando e manejando seus recursos conforme os ciclos anuais locais e regionais dentro de territórios cobertos total ou parcialmente com estrato arbóreo, solos cultiváveis de qualquer fertilidade e acesso à água. A distribuição dos sítios arqueológicos e as fontes históricas mostram que variáveis como topografia acidentada, áreas úmidas e frias da região sul do Brasil não foram barreiras, mas importantes complementos para ampliar as suas práticas sociais e econômicas.

Outro aspecto importante do MTG e do modelo de policultura agroflorestal compartilhado pelos povos Tupí, é que ele funciona a partir de unidades mínimas baseadas na família nuclear. Estas unidades mínimas são plásticas, articuladas por parentesco e política, sendo autônomas e autodeterminadas, mantendo a sua coesão até onde interessa ou o tamanho da população permite, geralmente aliando-se em redes interpessoais para formar uma casa grande, uma aldeia ou uma rede de aldeias. Da mesma maneira as suas roças novas, cada uma repetindo basicamente a mesma quantidade de espécies de plantas úteis, podem ter sua área ampliada proporcionalmente em escala e à medida que o tamanho da população cresce. Entre os Guaraní, cada tekohá produz basicamente os mesmos tipos de alimentos vegetais, talvez com variações pontuais no caso da ocupação de ambientes extremos em termos variáveis de cobertura vegetal, umidade e fertilidade dos solos, como no caso das várzeas com mata de galeria dos rios Paraguai, Paraná e Uruguai. Mesmo em áreas com espécies hiperdominantes, como nas florestas de araucária e de palmeiras, não havia especialização ou monocultura, mas a soma de várias espécies na produção anual das roças. Enfim, a abertura e manutenção das roças novas era a garantia da produção anual e da segurança alimentar, integrando o planejamento de um ciclo anual a ser renovado continuamente.

Foram os conhecimentos transmitidos entre as gerações a chave da longa duração do habitus amazônico, moldando padrões de assentamento, manejo ambiental, manutenção e reprodução de plantas úteis. E tais conhecimentos também favoreceram o reconhecimento e a adoção de novas espécies vegetais como alimento, medicina e matéria-prima, à medida que saíram dos domínios da Floresta Amazônica e passaram aos Biomas da Bacia Platina. Aí está, representado pelo conhecimento sistemático compartilhado, um poderoso ponto em comum que pode ser testemunhado atualmente nos diversos tekohás, distribuídos por uma vasta gama de ecossistemas e situações socioambientais. Contudo, ainda falta um programa de pesquisas ambientais locais e colaborativas, com os próprios Guaraní e diversos especialistas, para formular estratégias de segurança alimentar e econômica que alcancem a todos os tekohás. É importante que as comunidades mais bem estruturadas em termos ecológicos e de conhecimentos apoiem as menos aquinhoadas em processo inicial de assentamento ou residindo em lugares degradados, auxiliando-as a alcançar 
uma qualidade de vida autossustentada dentro dos parâmetros tradicionais, fator importante manifestado e desejado na fala dos Guaraní determinados a manter o seu ñande reko.

O modelo que apresentamos é geral, considerando os aspectos das práticas e conhecimentos que seriam os mais comuns e arraigados. Porém, é importante começar a investigar as particularidades caso a caso, para melhor conhecer localmente as estratégias de cada assentamento e os conhecimentos tradicionais. O ideal seria comparar os resultados para conhecer onde seria necessária uma atuação colaborativa para intercâmbio de plantas e de conhecimentos, a fim de nivelar para cima o que se sabe de Botânica e Ecologia, especialmente nas comunidades com faixa etária mais jovem, para garantir a segurança alimentar e a continuidade dos conhecimentos tradicionais.

As 1207 espécies levantadas na bibliografia publicada nos séculos XX e XXI, revelam uma amplitude vasta de conhecimentos botânicos. Mas o levantamento ainda não foi concluído, pois prosseguiremos examinando minuciosamente as fontes dos séculos XIX, XVIII, XVII e XVI. Essas espécies servem como referência para identificar as plantas potencialmente exploradas nos diversos Biomas da Bacia Platina, não necessariamente todas em um único local, mas com potencial para identificar parte delas por onde se assentaram os Guaraní, servindo inclusive como evidência de manejo antigo. Possivelmente, os Guaraní deram uma contribuição ao aumento da biodiversidade vegetal nas áreas onde viveram no passado, assim como fazem no presente, deixando sua assinatura na fitogeografia, assim como deixaram suas marcas materiais nos sítios arqueológicos, testemunhos materiais de sua longa ocupação territorial.

\section{Agradecimentos}

Às leituras e boas sugestões de Fabíola A. Silva, Amílcar D. de Mello, Marianne Sallum, Noélia Bortolloto, Andres Gascue, Silvana Suze, Caroline Caromano, Leandro Cascon, Eduardo Bespalez e Gregório C. T. Ceccantini. Agradecemos especialmente a Lúcio M. Ferreira, Mariano Bonomo e Héctor A. Keller.

\section{Referências}

APG III. 2009. An update of the Angiosperm Phylogeny Group classification for the orders and families of flowering plants: APG III. Botanical Journal of the Linnean Society, 162(2):105-121.

Anthony, D. W. 2010. The horse, The wheel and language. How Bronze-Age riders from the Eurasian steppes shaped the Modern World. Princeton: Princeton University Press.

Arenas, P. e Moreno-Azorero, R. 1976. Plantas utilizadas como abortivas, contraceptivas, esterelizantes y fecundizantes por los indígenas del Paraguay. Revista de la Sociedad Cientifica del Paraguay, v. 16, n. 1-2:3-19. 
Balée, W. 2000. Antiquity of traditional knowledge in Amazonia: The TupíGuaraní Family and Time. Ethnohistory, v. 47, n. 2:399-422.

Balée, W. 2013. Cultural forests of the Amazon. A historical ecology of people and their landscapes. Tuscaloosa: The University of Alabama Press.

Balée, W. e Cebolla Badie, M. 2009. The meaning of "tree" in two different Tupí-Guaraní languages from two different Neotropical forests. Amazônica, Revista de Antropologia, v. 1:96-135.

Betts, L. V. D. 1981. Dicionário Parintintin-Português, Português-Parintintin. Brasília: Summer Institute of Linguistics.

BFG. 2015. Growing knowledge: an overview of seed plant diversity in Brazil. Rodriguésia, v. 66, n. 4:1085-1113.

Bonomo, M., Angrizani, R. C., Apolinaire, E. e Noelli, F. S. 2015. A model for the Guaraní expansion in the La Plata Basin and littoral zone of southern Brazil. Quaternary International, v. 356:54-73.

Borges, M. V. 2006. Aspectos fonológicos e morfossintáticos da língua AváCanoeiro (Tupi-Guarani). Campinas: IELIUNICAMP (Doutorado em Linguística).

Brochado, J. P. 1984. An ecological model of the spread of pottery and agriculture into Eastern South America. Urbana-Champaign: University of Illinois at Urbana-Champaign (Doutorado em Antropologia).

Bueno, N. R. e Castilho, R.O. 2005. Medicinal plants used by the Kaiowá and Guarani indigenous populations in the Caarapó Reserve, Mato Grosso do Sul, Brazil. Acta Botanica Brasilica, v. 19, n. 1:39-44.

Cabral, A. S. A. C. 1996. Algumas evidências linguísticas de parentesco genético do Jo'é com línguas Tupí-Guaraní. Moara - Revista dos cursos de em Pós-Graduação em Letras da UFPA, v. 4:47-76.

Cadogan, L.. 1955. Breve contribuición ao estudio de la nomenclatura Guaraní en botánica. Asunción, Ministerio de Agricultura y Ganadería/Servicio Técnico Interamericano de Cooperación Agrícola.

Corrêa, A. A. 2014. Pindorama de Mboia e Iakaré: continuidade e mudança na trajetória das populações Tupí. São Paulo: MAE\USP (Doutorado em Arqueologia).

Corrêa, A. A. 2017. Datações na bibliografia arqueológica brasileira a partir dos sítios Tupí. Cadernos do Lepaarq, v. 14, n. 27:379-406.

Crandall-Stotler, B., Stotler, R. E. e Long, D. G.. 2009. Phylogeny and classification of the Marchantiophyta. Journal of Botany, v. 66, n. 1:155-198.

Dujak, M. e Marchi, P. 2010. Plantas utilizadas como barbasco por algunas comunidades indígenas del Paraguay. Steviana, v. 2:31-44.

Fargetti, C. M. 2001. Estudo morfológico e morfosintático da língua Juruna. Campinas: IellUnicamp (Tese de Doutorado). 
Fausto, C..2001. Inimigos fiéis. São Paulo: Edusp.

Fiebrig-Gertz, C. 1932. Nomenclatura Guarani de vegetales del Paraguay. Annaes do XX Congresso Internacional de Americanistas, vol. 3:305-329.

Frikel, P. 1959. Agricultura dos índios Munduruku. Boletim do Museu Paraense Emílio Goeldi, antropologia, v. 4, p. 1-35.

Garavaglia, J. C. 1987. Economía, sociedad y regiones. Buenos Aires: Ediciones de la Flor.

Garcia, W. G. 1985. Introdução ao universo botânico dos Kayová de Amambai: descrição e análise de um sistema classificatório. São Paulo, FFLCH-USP. (Tese de Doutorado).

Gatti, C. G. 1985. Enciclopedia Guarani-Castellano de conocimientos paraguayos. Asunción: Editorial Nuevo.

Giannecchini, D. 1916. Diccionario Chiriguano-Españoly Español-Chiriguano. Tarija: s/e.

Grenand, P. e Haxaire, C. 1977. Monographie d'un abattis Wayāpi. Journal d'agriculture traditionnelle et de botanique appliquée, v. 24, n. 4:285-310.

Jensen, C. 1989. O desenvolvimento histórico da língua Wayampi. Campinas: Edunicamp.

Kamayurá, W. 2012. Aweti e Tupi-Guarani: relações genéticas e contato linguístico. Brasília: UNB \LALI (Dissertação de Mestrado).

Keller, H. A. 2003. Mythical origin of Chusquea ramosissima (Poaceae), the ancient knife of the Guaranis. Economic Botany, v. 57, n. 4:461-471.

Keller,H.A. 2008. Las plantas usadas en la construcción y el acondicionamientode las viviendas y templos guaraníes en Misiones. Bonplandia, Corrientes, v. 17, n. 1:65-81.

Keller, H. A. 2009a. El "Yvyraro", un árbol ictiotóxico de los Guaraníes de Misiones, Argentina. Darwiniana, v. 47, n. 1, p.31-34.

Keller, H. A. 2009b. Plantas textiles de los Guaraníes de Misiones, Argentina. Bonplandia, v. 18, n. 1:29-37.

Keller, H. A. 2010a. Plantas usadas por los guaraníes de Misiones (Argentina) para la fabricación y el acondicionamiento de instrumentos musicales. Darwiniana, nueva serie, v. 48, 1:7-16.

Keller, H. A. 2010b. Plantas colorantes utilizadas por los guaraníes de Misiones, Argentina. Bonplandia, v. 19, n. 1:11-25.

Keller, H. A. 2010c. Plantas relacionadas con tabúes del ciclo reproductivo de los Guaraníes de Misiones, Argentina. Boletín de la Sociedad Argentina de Botánica, v. 45, n. 1-2:201-208.

Keller, H. A. 2011a. Problemas de la etnotaxonomía guaraní:" Las plantas de los animales". Bonplandia, v. 20, n. 2:111-136. 
Keller, H. A. 2011b. Juegos y deportes de los guaraníes de Misiones, Argentina: notas etnobotánicas complementarias. Bonplandia, v. 20, n. 2:231-249.

Keller, H. A. 2012. El origen y la decadencia de los cultivos Guaraníes, un relato mítico de los Avá Chiripá de Misiones, Argentina. Bonplandia, v. 21, n. 1:27-44.

Keller, H. A. 2013. "La Lanza del serpentario", origen mítico de Xylopia brasili ensis (Annonaceae), una versión de los Guaraníes Ava Chiripa de Misiones. Boletín de la Sociedad Argentina de Botánica, v. 48, n. 2:355-364.

Keller, H. A. 2015. et al. Abordaje participativo en Estudios Etnobotánicos: el caso de las comunidades guaraníes de Misiones, Argentina. Suplemento Antropológico, v. 50:523-549.

Keller, H. A. e Crockett, S. L. 2015. Hypericum robsonii spec. nova sect. Trigynobrathys (Hypericaceae) from the Misiones Province in Argentina. Phyton, v. 1, n. 55:17-29.

Keller, H. A., Pirondo, A. e Stampella, P. 2018. El cultivo del rícino y el amba'y em comunidades Guaraní del Nordeste Argentino, aproximación etnobotánica de su história y cosmologia. Bonplandia, v. 27, n. 1:23-30.

Keller, H. A. e Prance, G. T. 2008. Plants associated with fish by Guaraníes of Misiones, Argentina. Ethnobotany, v. 20:1-8.

Keller, H. A. e Prance, G. T. 2012. Ethnobotany of the species of Solanum, subgenus Bassovia, section Pachyphylla (Solanaceae) of Misiones Province, Argentina. Bonplandia, Corrientes, v. 21, n. 1, p.45-54.

Keller, Hector A. et al. 2010. Etnobotanical resources of the Multiple-use Guaraní Reserve, Misiones (Argentina): their importance to the indigenous communities of Caramelito and Taruma Poty. Ethnobotany, v. 22:38-54.

Keller, H. A., Torres, E. I. Meza. e Prance, G. T. 2011. Ethnopteridology of the Guaranís of Misiones Province, Argentina. American Fern Journal, v. 101, n. 3:193-204.

Koch-Grünberg, T. 1932. Wörtenlisten "Tupy”, Maué, und Puruborá. Journal de la Société des Américanistes, v. 24 :31-50.

Lévi-Staruss, C. 1950. The use of wild plants in Tropical South America. In: Steward, Julian H. (ed). Handbook of South American Indians. Vol 3. The Tropical Forest Tribes. Washington: Smithsonian Institution. Bureau of American Ethnology. Bulletin, v. 143:465-486.

Lorenzana, M. 1951. Informe de um jesuíta anônimo sobre as cidades do Paraguai e do Guairá espanhóis, índios e mestiços. Dezembro, 1620. In: Jaime Cortesão (Org.). Jesuitas e Bandeirantes no Guairá (1594-1640). Rio de Janeiro, Biblioteca Nacional. pp. 162-17.

Maffi, L. 2001. Introduction. Introduction to Biocultural Diversity. Washington D.C.: Smithsonian Institution. pp. 4-5. 
Martínez-Crovetto, R. 1968a. La alimentación entre los índios Guaraníes de Misiones (República Argentina). Etnobiológica, v. 4:1-24.

Martínez-Crovetto, R. 1968b. Introducción a la etnobotánica aborigen del nordeste argentino. Etnobiológica, v. 11:1-10.

Martínez-Crovetto, R. 1968c. Notas sobre la agricultura de los índios Guaraníes de Misiones (República Argentina). Etnobiológica, v. 10:1-11.

Melià, B. 1989. Potyró: La cuestión del trabajo indígena Guaraní. Anais do VIII Simpósio Nacional de Estudos Missioneiros. Santa Rosa. pp. 295-326.

Melià, B. 2016. Camino Guaraní. De lejos venimos, hacia más lejos caminamos. Asunción: CEPAG.

Melià, B., Grünberg. e G. Grünberg, F. 2008. 1975. Paĩ - Tavyterã. Etnografía Guaraní del Paraguay contemporáneo. Asunción: Ceaduc\Cepag.

Miraglia, L. Caza, recolección y agricultura entre los indígenas del Paraguay. Suplemento Antropológico, v. 10:1-2, 9-91.

Montoya, A. R. 1989. Conquista espiritual. Posadas: Instituto Antonio Ruiz de Montoya.

Montoya, A. R. 2002. Vocabulario de la lengua Guaraní (1640). Asunción: CEPAG.

Montoya, A. R. 2011. Tesoro de la lengua Guaraní (1639). Asunción: Cepag.

Muller, F. 1997. Drogas y medicamentos de los índios Guaraní (Mbyá, Pãi y Chiripá) en las regiones de la selva del Paraguay. Parodiana, v. 10:1-2, 197:209.

Nicholson, V. 1978. Aspectos da língua Asuriní. Brasília: SIL.

Nicholson, V. 1982. Breve estudo da língua Asurini do Xingu. (Ensaios Linguísticos). Brasília: SIL.

Nimuendajú, C. 1927. Reconhecimento dos rios Içána, Ayarí, e Uaupés, março a julho de 1927. Apontamentos linguísticos. Journal de la Société des Américanistes, v. 44:149-178.

Noelli, F. S. 1993. Sem Tekohá não há Tekó (em busca de um modelo etnoarqueológico da subsistência e da aldeia Guaraní aplicado a uma área de domínio no delta do Jacuí-RS). Porto Alegre: Pontifícia Universidade Católica do Rio Grande do Sul (Mestrado em História).

Noelli, F. S. 1994. El Guaraní agricultor. Acción-Revista Paraguaya de reflexión $y$ diálogo, v. 144:17-20.

Noelli, F. S. 1999-2000. A ocupação humana na região sul do Brasil: Arqueologia, debates e perspectivas - 1872 - 2000. Revista USP, v. 44, n. 2:218-269.

Noelli, F. S. 2004. La distribución geográfica de las evidencias arqueológicas Guaraní. Revista de Indias, v. 64, n. 230:17-34.

Noelli, F. S. e Brochado, J. P. 1998. O cauim e as beberagens dos Guaraní e 
Tupinambá: equipamentos, técnicas de preparação e consumo. Revista do Museu de Arqueologia e Etnologia, v. 8:117-128.

Noelli, F. S. e Landa, B. S. 1993. Introdução às atividades têxteis Guarani. Anais do X Simpósio Nacional de Estudos Missioneiros. Santa Rosa, UNIJUÍ. pp. 472-478.

Noelli, F. S. 1998c. Aportes históricos e etnológicos para o reconhecimento da classificação Guarani de comunidades vegetais no século XVII. Fronteiras, v. 2 , n. 4:275-96.

Noelli, F. S. 1998a. Múltiplos usos de espécies vegetais pela farmacologia guarani através de informações históricas. Diálogos, v. 2, n. 1:177-199.

Noelli, F. S. e CORRÊA,A.A. s.d. Catálogo de vasilhas cerâmicas arqueológicas e etnográficas Tupí. (no prelo).

Nogueira, A. F. S. 2011. Wayoro émẽto. Fonologia segmental e morfosintaxe verbal. São Paulo: FFLCH $\backslash$ USP (Dissertação de Mestrado).

Oliveira, D. 2009. As florestas que pertencem aos deuses: etnobotânica e territorialidade Guarani na Terra Indígena M'biguaçu/SC. Florianópolis: Ccb\Ufsc (Tcc).

Perasso, J. A. e Vera, J. 1988. La Cultura Guaraníen el Paraguay Contemporáneo. (Etnografia Ava-Kue-Chiripa). Asunción: RP Ediciones.

Pereira, A. A. 1984. Contribuição ao estudo dos fungos agaricales da mata nativa de Araucaria angustifolia (Bertol) O. Kuntze. Da Floresta Nacional de São Francisco de Paula. Rio Grande do Sul. Pesquisas, botánica, v. 35:1-73.

Pereira, A. A. 1988. O gênero Pleurotus (Fr.) Kummer no Rio Grande do Sul, Brasil. Cadernos de Pesquisa, v. 1, n. 1:19-45.

Pereira, A. A. 1990. O gênero Crepidotus no Rio Grande do Sul, Brasil. Cadernos de Pesquisa, v. 2, n. 1:65-85.

Pereira, S. G., et al. 2016. Ecologia Histórica Guarani: as plantas utilizadas no Bioma Mata Atlântica do litoral sul de Santa Catarina, Brasil (Parte 1). Cadernos do LEPAARQ, v. 13, n. 26:197-246.

Pirondo, A.; Keller, H. A. 2014. Aproximación al paisaje a través del conocimiento ecológico tradicional en humedales de un área protegida del Nordeste Argentino. Etnoecológica, v. 10, n. 3:1-11.

Pirondo, A. et al. 2018. El cultivo del ricino y el amba'y en comunidades guaraníes del Nordeste Argentino, aproximación etnobotánica de su historia y cosmología. Bonplandia, v. 27, n. 1:23-30.

Posey, D. A. 1987. Manejo da floresta secundária, capoeiras, campos e cerrados (Kayapó). Suma Etnológica Brasileira, v. 1. Petrópolis: Vozes. pp. 173-185.

Reed, R. K. 1999. Prophets of agroforestry. Guarani communities and commercial gathering. Austin: University of Texas Press. 
Rengger, J. R. 2010. Viaje al Paraguay en los años 1818 a 1826. Asunción: Tiempo de História.

Rice, J. D. 1934. O idioma Tembé (Tupi-guarani). Journal de la Société des Américanistes, v. 26, 1:109-180.

Rindos, D. 1980. Symbiosis, instability, and the origins and spread of agriculture: a new model. Current Anthropology, v. 21, 6:751-772.

Rival, L. 1998. Domestication as a historical and symbolic process: wild gardens and cultivated forests in the Ecuatorian Amazon. In: W. Balée (Ed). Advances in historical ecology. New York: Columbia University Press. pp. 232-250.

Rodrigues, A. D. 1966. Classificação da língua dos Cinta-Larga. Revista de Antropologia, v. 14: 27-30.

Rodrigues, A. D. 1984-1985. As relações internas na família Tupi-Guarani. Revista de Antropologia, v. 27,28:33-53.

Rodrigues, A. D. 2007. As consoantes do Proto-Tupí. In: Cabral, A. S. C.; Rodrigues, A. D. (org). Línguas e Culturas Tupí. Campinas/Brasília: Curt Nimuendajú/ LALI. pp. 167-203.

Rodrigues, A. D. 2010. Linguistic reconstruction of elements of prehistoric Tupí culture. In: Carlin, E. B.; van der Kerke, S. (eds). Linguistics and archaeology in the Americas: the historization of language and society. Leiden: Brill, v. 2:110.

Rodrigues, A. D, Cabral, A. S. Tupían. In: Campbell, L, e Grondona, V. (eds). 2012. The indigenous languages of South America, v.2. Berlin\Boston: Mouton de Gruyter. pp. 495-574.

Schermair, A. 1957. Vocabulario Sirionó-Castellano. Innsbruck: Innsbrucker Beiträge zur Kulturwissenschaft.

Schmidt, M. 2013. Amazonian Dark Earths: pathways to sustainable development in tropical rainforests? Boletim do Museu Paraense Emílio Goeldi, Ciências Humanas, v. 8, n. 1:11-38.

Schmidt, M. V. C. 2001. Etnosilvicultura Kaiabi no Parque Indigena do Xingu: subsídios ao manejo de recursos florestais. São Carlos: UFSCar (Mestrado em Ciências da Engenharia Ambiental).

Silva, F. A. 2000. As tecnologias e seus significados. Um estudo da cerâmica dos Asuriní do Xingu e da cestaria dos Kayapo-Xikrin sob uma perspectiva etnoarqueologica. Tese de Doutorado. Universidade de São Paulo.

Silva, F. A. e Noelli, F. S. 2017. Arqueologia e Linguística: Construindo as trajetórias histórico-culturais dos povos Tupí. Crítica e Sociedade: Revista de Cultura Política, v. 7, n. 1:55-87.

Smith, A. R., Pryer, K. M., Schuettpelz, E., Korall, P., Schneider, H. e Wolf, P. G. A classification for extant ferns. Taxon, v. 55, p. 705-731.

Strelnikov, S. I. 1928. Les Kaa-îwuá du Paraguay. Atti del XXII Congresso Internazionale degli Americanisti, vol. 2:333-366. 
Stuchi, F. F. 2010. A ocupação da terra indígena Kaiabi. História indígena e etnoarqueologia. São Paulo: Usp\Mae (Dissertação de Mestrado).

Susnik, B. 1982. Los Aborígenes del Paraguay. IV: Cultura Material. Asunción: Museo Etnográfico Andrés Barbero.

Ter Steege, H. Et Al. 2013. Hyperdominance In The Amazonian Tree Flora. Science, V. 342, n. 6156:1243092-1243092.

Vera, C. e Brand, A. 2012. Aramanday Guasu( Rhynchophorus Palmarum) Como Alimento Tradiconal Entre Os Guarani Ñandéva Na Aldeia Pirajuí. Tellus, v. 12:12-68.

Viveiros De Castro, E. B. 1986. Araweté. Os Deuses Canibais. Rio de Janeiro, Zahar/ANPOCS.

Watson, J. 1952. Cayuá culture. American Anthropologist, 54(2). Memoir 73, Lancaster.

Wendrich, W. 2012. Archaeology and apprenticeship: body knowledge, identity, and communities of practice. Tucson: The University of Arizona Press. pp. 1-19.

Zimpel, C. A. 2018. A fase Bacabal e seus correlatos na Amazônia. São Paulo: MAEIUSP (Doutorado em Arqueologia). 